\title{
Ochrocephalamines B-D, three alkaloids from Oxytropis ochrocephala Bunge
}

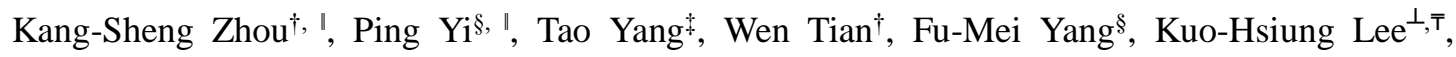
Bao-Yu Zhao ${ }^{\nabla}$, Yue-Hu Wang ${ }^{\ddagger}, *$, and Cheng-Jian Tan ${ }^{\dagger, *}$

†School of Ethnic Medicine, Guizhou Minzu University, Guiyang 550025, People’s Republic of China

\#ey Laboratory of Economic Plants and Biotechnology and Yunnan Key Laboratory for Wild Plant Resources, Chinese Academy of Sciences, Kunming 650201, People's Republic of China

$\S_{\text {}}^{\S}$ The Key Laboratory of Chemistry for Natural Product of Guizhou Province and Chinese Academy of Science, Guiyang 550002, People's Republic of China

${ }^{\perp}$ Natural Products Research Laboratories, UNC Eshelman School of Pharmacy, University of North Carolina, Chapel Hill, NC 27599, United States

${ }^{\bar{T}}$ Chinese Medicine Research and Development Center, China Medical University and Hospital, Taichung, Taiwan

${ }^{\nabla}$ College of Veterinary Medicine, Northwest A\&F University, Yangling 712100, People's Republic of China

"These authors contributed equally to this work

*Corresponding Author, Phone: (+86) 851-83610313.

Email address: tcj1229@163.com,wangyuehu@mail.kib.ac.cn 


\section{Supporting Information}

S1. Experimental section

Figure S2. ${ }^{1} \mathrm{H}$ NMR spectrum of Ochrocephalamine B (1) in $\mathrm{CD}_{3} \mathrm{OD}$

Figure S3. ${ }^{13} \mathrm{C}$ NMR spectrum of Ochrocephalamine B (1) in $\mathrm{CD}_{3} \mathrm{OD}$

Figure S4. HSQC spectrum of Ochrocephalamine B (1) in $\mathrm{CD}_{3} \mathrm{OD}$

Figure S5. HMBC spectrum of Ochrocephalamine B (1) in $\mathrm{CD}_{3} \mathrm{OD}$

Figure S6. ${ }^{1} \mathrm{H}-{ }^{1} \mathrm{H}$ COSY spectrum of Ochrocephalamine B (1) in $\mathrm{CD}_{3} \mathrm{OD}$

Figure S7. ROESY spectrum of Ochrocephalamine B (1) in $\mathrm{CD}_{3} \mathrm{OD}$

Figure S8. ${ }^{1} \mathrm{H}$ NMR spectrum of Ochrocephalamine $\mathrm{C}(\mathbf{2})$ in $\mathrm{CD}_{3} \mathrm{OD}$

Figure S9. ${ }^{13} \mathrm{C}$ NMR spectrum of Ochrocephalamine $\mathrm{C}(2)$ in $\mathrm{CD}_{3} \mathrm{OD}$

Figure S10. HSQC spectrum of Ochrocephalamine C (2) in $\mathrm{CD}_{3} \mathrm{OD}$

Figure S11. HMBC spectrum of Ochrocephalamine C (2) in $\mathrm{CD}_{3} \mathrm{OD}$

Figure S12. ${ }^{1} \mathrm{H}-{ }^{1} \mathrm{H}$ COSY spectrum of Ochrocephalamine $\mathrm{C}(2)$ in $\mathrm{CD}_{3} \mathrm{OD}$

Figure S13. ROESY spectrum of Ochrocephalamine C (2) in $\mathrm{CD}_{3} \mathrm{OD}$

Figure S14. HRESI of Ochrocephalamine D (3)

Figure S15. ${ }^{1} \mathrm{H}$ NMR spectrum of Ochrocephalamine D (3) in $\mathrm{CD}_{3} \mathrm{OD}$

Figure S16. ${ }^{13} \mathrm{C}$ NMR spectrum of Ochrocephalamine D $(3)$ in $\mathrm{CD}_{3} \mathrm{OD}$

Figure S17. HSQC spectrum of Ochrocephalamine $\mathrm{D}(\mathbf{3})$ in $\mathrm{CD}_{3} \mathrm{OD}$

Figure S18. HMBC spectrum of Ochrocephalamine $\mathrm{D}(\mathbf{3})$ in $\mathrm{CD}_{3} \mathrm{OD}$

Figure S19. ${ }^{1} \mathrm{H}-{ }^{1} \mathrm{H}$ COSY spectrum of Ochrocephalamine D $(3)$ in $\mathrm{CD}_{3} \mathrm{OD}$

Figure S20. ROESY spectrum of Ochrocephalamine D (3) in $\mathrm{CD}_{3} \mathrm{OD}$

Figure S21. ${ }^{1} \mathrm{H}$ NMR spectrum of Aloperine (4) in $\mathrm{CDCl}_{3}$

Figure S22. ${ }^{13} \mathrm{C}$ NMR spectrum of Aloperine (4) in $\mathrm{CDCl}_{3}$

S23. Physical data of 1-3

S24. ECD spectra calculation of $\mathbf{1 - 3}$

ECD spectra calculation of $\mathbf{1}$

ECD spectra calculation of $\mathbf{2}$

ECD spectra calculation of $\mathbf{3}$ 


\section{S1. Experimental section}

\section{A. General Experimental Procedures}

Optical rotation was carried out on a Perkin-Elmer model 241 polarimeter. IR spectrum was measured in a Bio-Rad FTS-135 spectrometer with $\mathrm{KBr}$ pellets. FAB, ESI and high-resolution mass spectra were recorded using a Finnigan MAT 90 instrument and VG Autospec-3000 spectrometer respectively. ${ }^{1} \mathrm{H}$ and ${ }^{13} \mathrm{C}$ NMR spectra were measured on Bruker AM-400 and DRX-500 spectrometers, while 2D NMR spectra were recorded on Bruker DRX-500 instrument. Chemical shifts were reported using TMS as internal standard. Column chromatography was performed on silica gel H (10-40 $\mu \mathrm{m}$; Qingdao Marine Chemical Inc.), $\mathrm{C}_{18}$ silica gel (20-45 $\mu \mathrm{m}$; Chromatorex, Japan) and Sephadex LH-20 (40-70 $\mu \mathrm{m}$, Amersham Pharmacia Biotech AB, Uppsala, Sweden). Semi-peparative HPLC was performed on a XBridge Prep C-18 (Waters Corp. Ireland) column (i.d. $10 \times 250 \mathrm{~mm}$ ). Precoated silica gel $\mathrm{GF}_{254}$ and $\mathrm{HF}_{254}$ plates (Qingdao Haiyang Chemical Plant, Qingdao, People's Republic of China) were used for TLC.

\section{B. Plant Material}

The whole plants of $O$. ochrocephala, collected in Huangzhong, Qinghai Province, China, in October 2012, were identified by Prof. Chong-Hui Mo, Qinghai University. The voucher specimen (ZhaoBY-201203) was deposited at Northwest A\&F University, Yangling, Shaanxi, China.

\section{Extraction and Isolation}

The whole plant (20.0 kg) of $O$. ochrocephala was percolated three times with $95 \%$ $\mathrm{EtOH}$ to give a crude extract $(3.0 \mathrm{~kg})$. The extract was concentrated to dryness under reduced pressure, followed by partitioning between $\mathrm{CH}_{2} \mathrm{Cl}_{2}$ and $2 \% \mathrm{HCl}$. The aqueous phase was then adjusted to $\mathrm{pH} 11$ with $3 \% \mathrm{NaOH}$ and extracted with $\mathrm{CH}_{2} \mathrm{Cl}_{2}$ to give crude alkaloids (100 g). The crude alkaloids were subjected to a silica gel column eluted with $\mathrm{CHCl}_{3} / \mathrm{MeOH}(1: 0$ to $0: 1)$ to obtain fractions $\mathrm{A}, \mathrm{B}$ and $\mathrm{C}$. Fraction A was chromatographed on silica gel [Petroleum ether/Acetone (10:1)] and Sepdax LH-20 $(\mathrm{MeOH})$, then RP-18 (80\% MeOH) columns to yield ochrocephalamine B (1, $7.0 \mathrm{mg})$, and semi-preparative HPLC (XBridge C-18, Waters Corp. Ireland, $5 \mu \mathrm{m}, 10 \mathrm{~mm} \times$ 
$250 \mathrm{~mm}$ column, $\mathrm{MeOH} / \mathrm{H}_{2} \mathrm{O}$ (containing $0.05 \% \mathrm{TFA}$ ) $10 / 90,1 \mathrm{~mL} / \mathrm{min}$ ) to yield ochrocephalamine C (2, $3.0 \mathrm{mg}$, retention time $10.923 \mathrm{~min})$, ochrocephalamine D (3, $3.5 \mathrm{mg}$, retention time $4.960 \mathrm{~min})$ and aloperine $(22.9 \mathrm{mg}$, retention time $1.746 \mathrm{~min})$.

\section{Antiproliferative Activity Assay.}

Human tumor cells were cultured in 96-well plate at densities of 4000-11000 cells per well in the presence of test compound. After three days in culture, attached cells were fixed in $10 \%$ trichloroacetic acid and then stained with $0.04 \%$ sulforhodamine B. The protein-bound dye was solubilized with $10 \mathrm{mM}$ Tris base and absorbance at 515 $\mathrm{nm}$ was measured using a microplate reader operated by Gen5 software (BioTek). The mean $\mathrm{IC}_{50}$ is the concentration of agent that reduces cell growth by $50 \%$ under the experimental conditions and is the average from at least three independent determinations that were reproducible and statistically significant. The following human tumor cell lines were used in the assay: A549 lung adenocarcinoma, KB originally isolated from epidermoid carcinoma of the nasopharynx, multidrug-resistant KB subline KB-VIN, and MDA-MB-231 triple-negative breast cancer (estrogen receptor (ER)-, progesterone receptor (PgR)- and erbB2(HER2)-negative). All cells were obtained from Lineberger Comprehensive Cancer Center (UNC-CH) or from ATCC (Rockville, MD), except KB-VIN, which was a generous gift of Professor Y-C. Cheng, Yale University. Cells were cultured in PRMI-1640 medium containing $25 \mathrm{mM}$ HEPES, $2 \mathrm{mM}$ L-glutamine (Gibco), supplemented with $10 \%$ fetal bovine serum (Sigma), $100 \mu \mathrm{g} / \mathrm{mL}$ streptomycin, 100 $\mathrm{IU} / \mathrm{mL}$ penicillin and $0.25 \mu \mathrm{g} / \mathrm{mL}$ amphotericin B (Cellgro). KB-VIN stock cells were maintained in the medium containing $100 \mathrm{nM}$ vincristine.

\section{E. Anti-HBV activity assay}

Materials. FBS was purchased from Zhejiang Tianhang Biotechnology co. MEM medium was obtained from Sigma. The diagnostic kit for HBsAg and HBeAg (ELISA) were purchased from InTec PRODUCTS, INC. IFN- $\alpha$ and 3-TC were obtained from Harbin Pharmaceutical Group Bioengineering Co. and GSK, respectively. MD 190 ELISA reader, TS100 Inverted Phase Contrast Microscope from Nikon Instech Co., Ltd., Forma Series II Water Jacketed $\mathrm{CO}_{2}$ Incubator from Thermo electron 
corporation (Marietta, Ohio, USA). Compound solution were prepared in DMSO. Upon dilution into culture medium, the final DMSO concentration was $\leq 0.1 \%$ DMSO (v/v), a concentration without effect on cell replication.

Cytotoxicity Assay. Cellular toxicity of compounds was assessed by MTT method. All stock cultures were grown in MEM medium supplemented with $10 \%$ (v/v) fetal bovine serum, $0.03 \%$ L-glutamine, $100 \mu \mathrm{g} / \mathrm{mL}$ penicillin, $100 \mu \mathrm{g} / \mathrm{mL}$ streptomycin, and $380 \mu \mathrm{g} / \mathrm{mL} \mathrm{G} 418$ at $37^{\circ} \mathrm{C}$ in a humidified incubator containing $5 \% \mathrm{CO}_{2}$ (Zhongguo Bing Du Xue, 1998, 13, 45-49; Bioorg. Med. Chem. Lett., 2006, 16, 1231-1235). HepG2.2.15 cells were seeded in 96 well plates at a density of $2 \times 10^{5}$ $(100 \mu \mathrm{L})$ per well. After $24 \mathrm{~h}$, the supernatants $(70 \mu \mathrm{L})$ were discarded, the fresh medium $(60 \mu \mathrm{L})$ and compound solution $(10 \mu \mathrm{L})$ were added into the well, respectively. The medium was refreshed every $3 \mathrm{~d}$ using the same handle mentioned before. After $5 \mathrm{~d}$, twenty microliters of MTT reagent $(5 \mathrm{mg} / \mathrm{mL}$ in PBS) was added to each well to analyze the cytotoxicity of different drugs. Each experiment was performed in triplicate.

Measurement of $\boldsymbol{H B V}$ Antigen. HepG2.2.15 cells (HepG2 cells transfected with cloned HBV DNA to produce HBV particles) were seeded in 96 well plates at a density of $2 \times 10^{5}(100 \mu \mathrm{L})$ per well. After $24 \mathrm{~h}$, the supernatants $(70 \mu \mathrm{L})$ were discarded, the fresh medium $(60 \mu \mathrm{L})$ and compound solution $(10 \mu \mathrm{L})$ were added into the well, respectively. The medium was refreshed every $3 \mathrm{~d}$ using the same handle mentioned before. After 5d, the culture supernatants were harvested to detect the HBsAg and HBeAg secretion using diagnostic kit for HBsAg and HBeAg (ELISA) (InTec PRODUCTS, INC) as described in the instruction of the kit. Each test was performed in three times.

\section{References}

[1] Ding, P.-L.; Liao, Z. -X.; Huang, H.; Zhou, P.; Chen, D. -F. Bioorg. Med. Chem. Lett. 2006, 16, 1231-1235.

[2] Sells, M. -A.; Chen, M. -L.; Acs, G. Proc. Natl. Acad. Sci. 1987, 84, 1005-1009.

[3] Cui, X. -Y.; Inagaki, Y.; Xu, H, -L.; Wang, D. -L.; Qi, F.-H.; Kokudo, N.; Fang, D.-Z.; Tang, W. Biol. Pharm. Bull. 2010, 33, 1728-1732. 
Figure S2. ${ }^{1} \mathrm{H}$ NMR spectrum of Ochrocephalamine $\mathrm{B}(\mathbf{1})$ in $\mathrm{CD}_{3} \mathrm{OD}$.

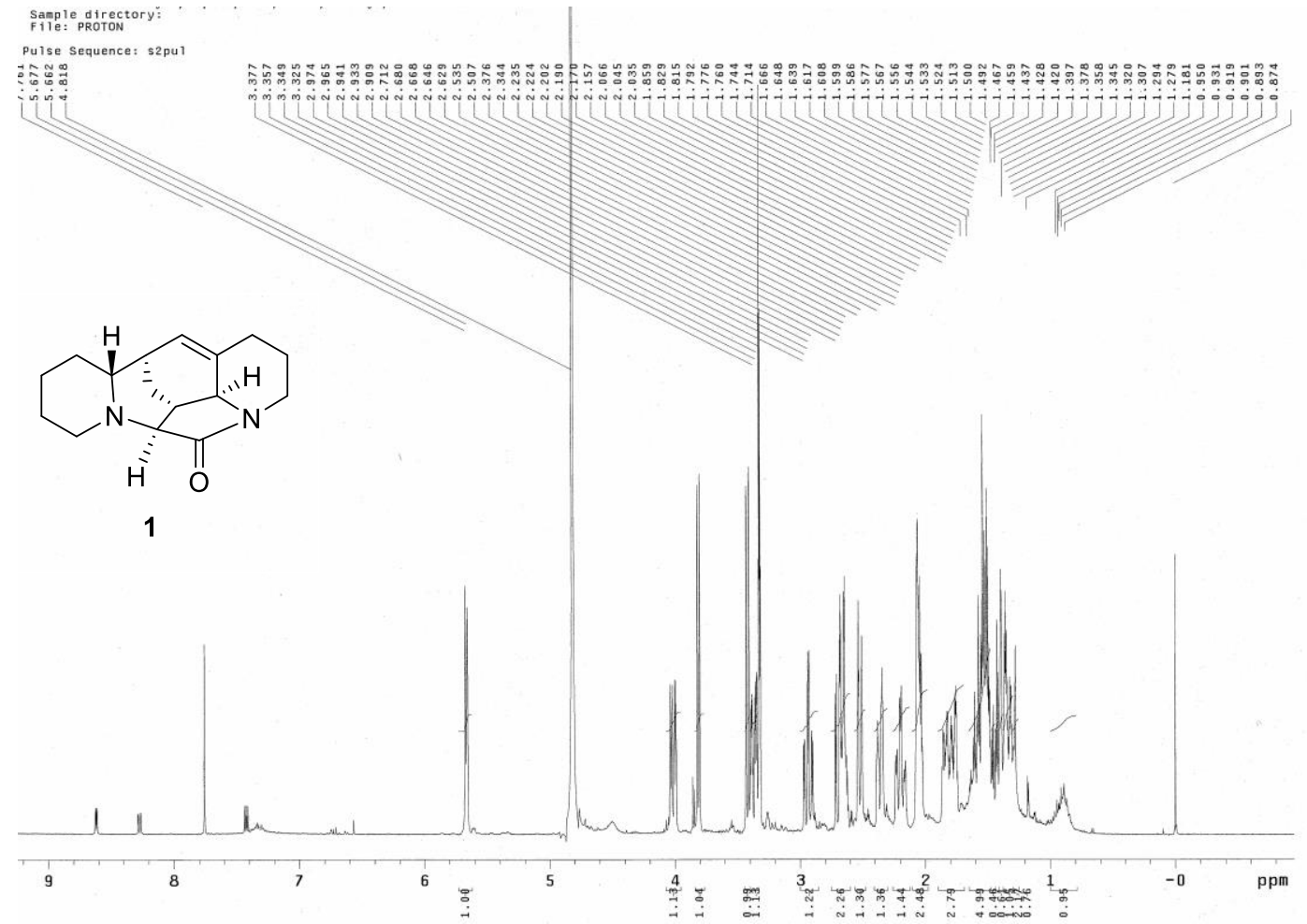

Figure S3. ${ }^{13} \mathrm{C}$ NMR spectrum of Ochrocephalamine $\mathrm{B}(\mathbf{1})$ in $\mathrm{CD}_{3} \mathrm{OD}$.

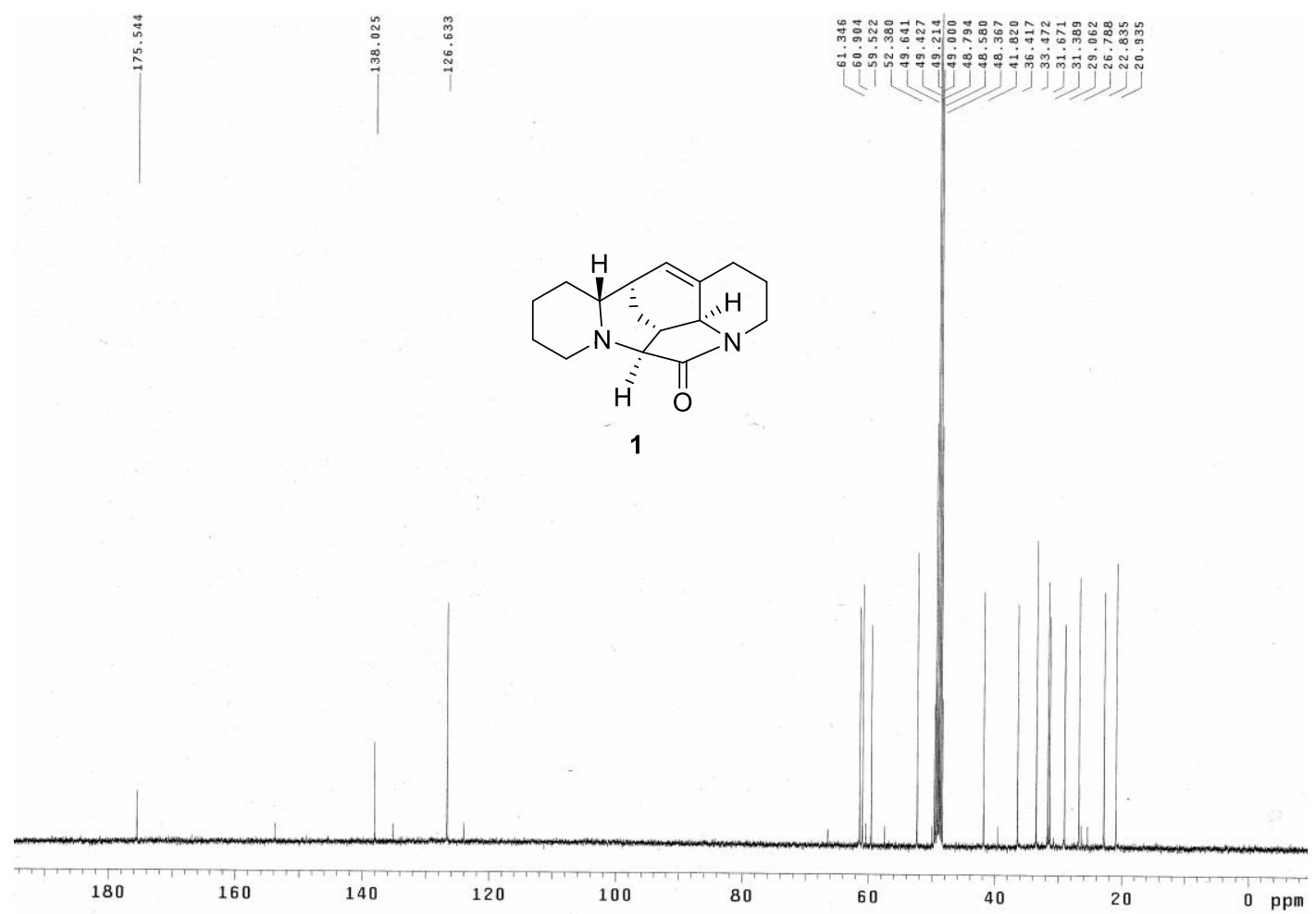



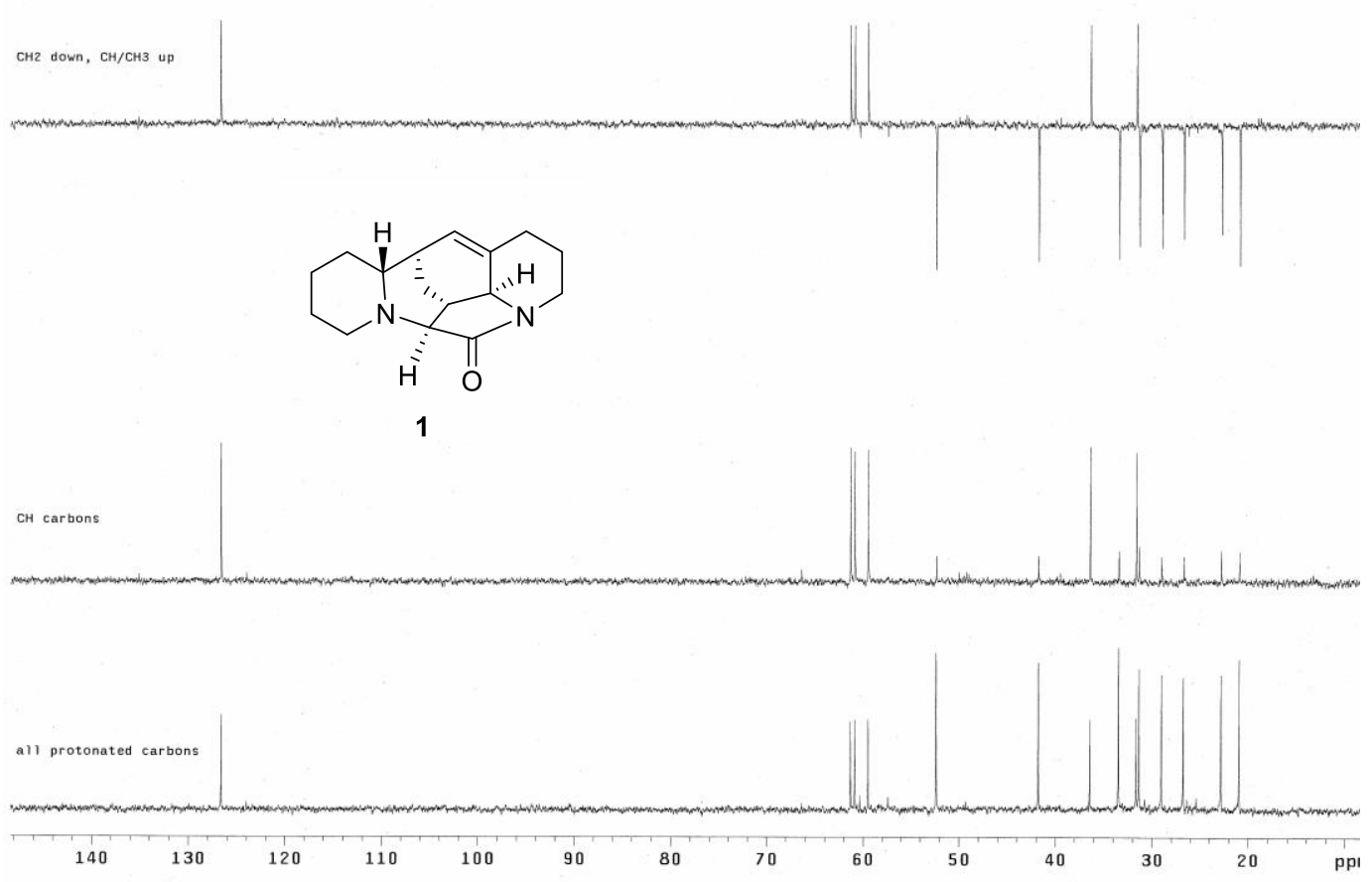

Figure S4. HSQC spectrum of Ochrocephalamine B (1) in $\mathrm{CD}_{3} \mathrm{OD}$.

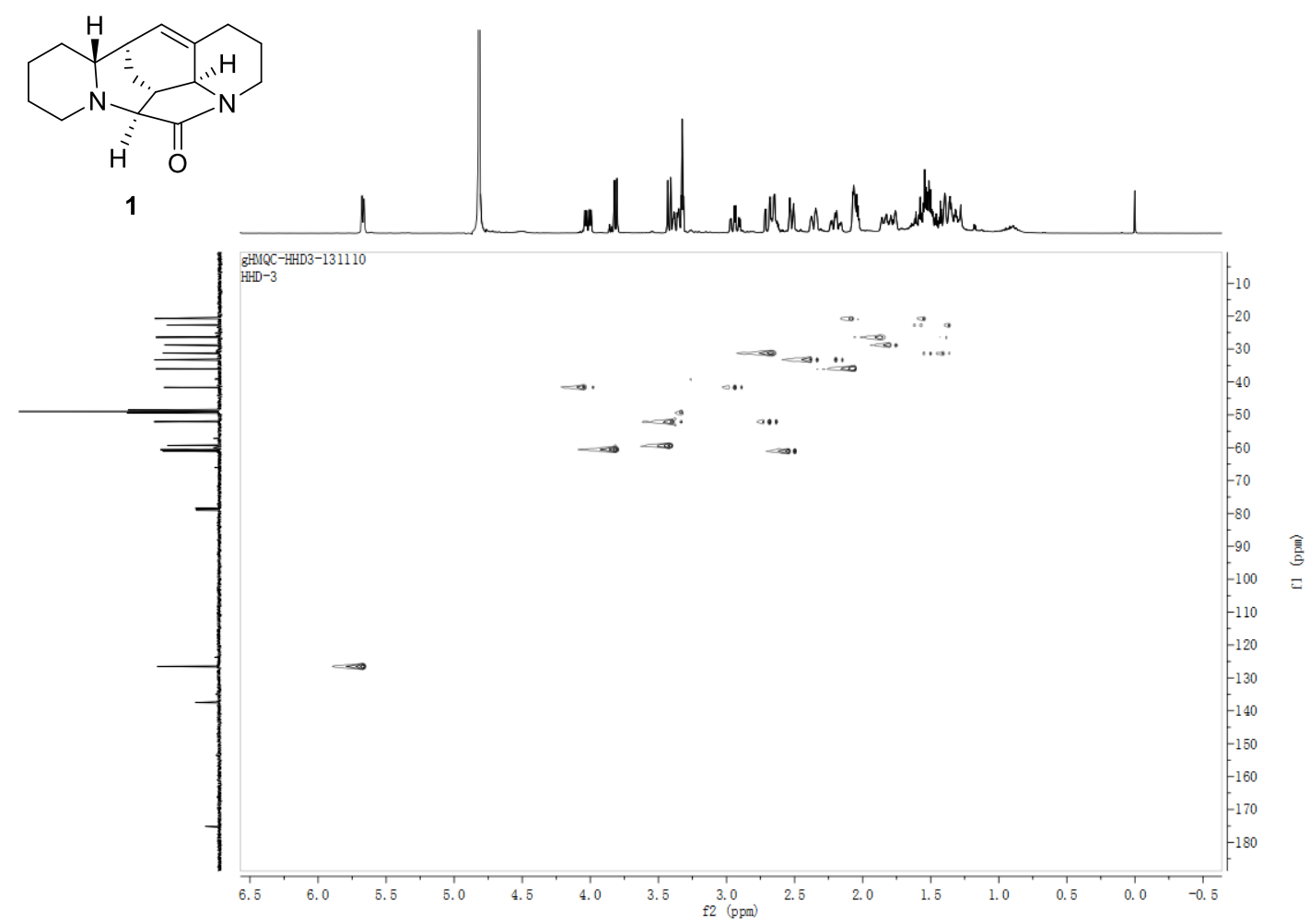


Figure S5. HMBC spectrum of Ochrocephalamines B (1) in $\mathrm{CD}_{3} \mathrm{OD}$.

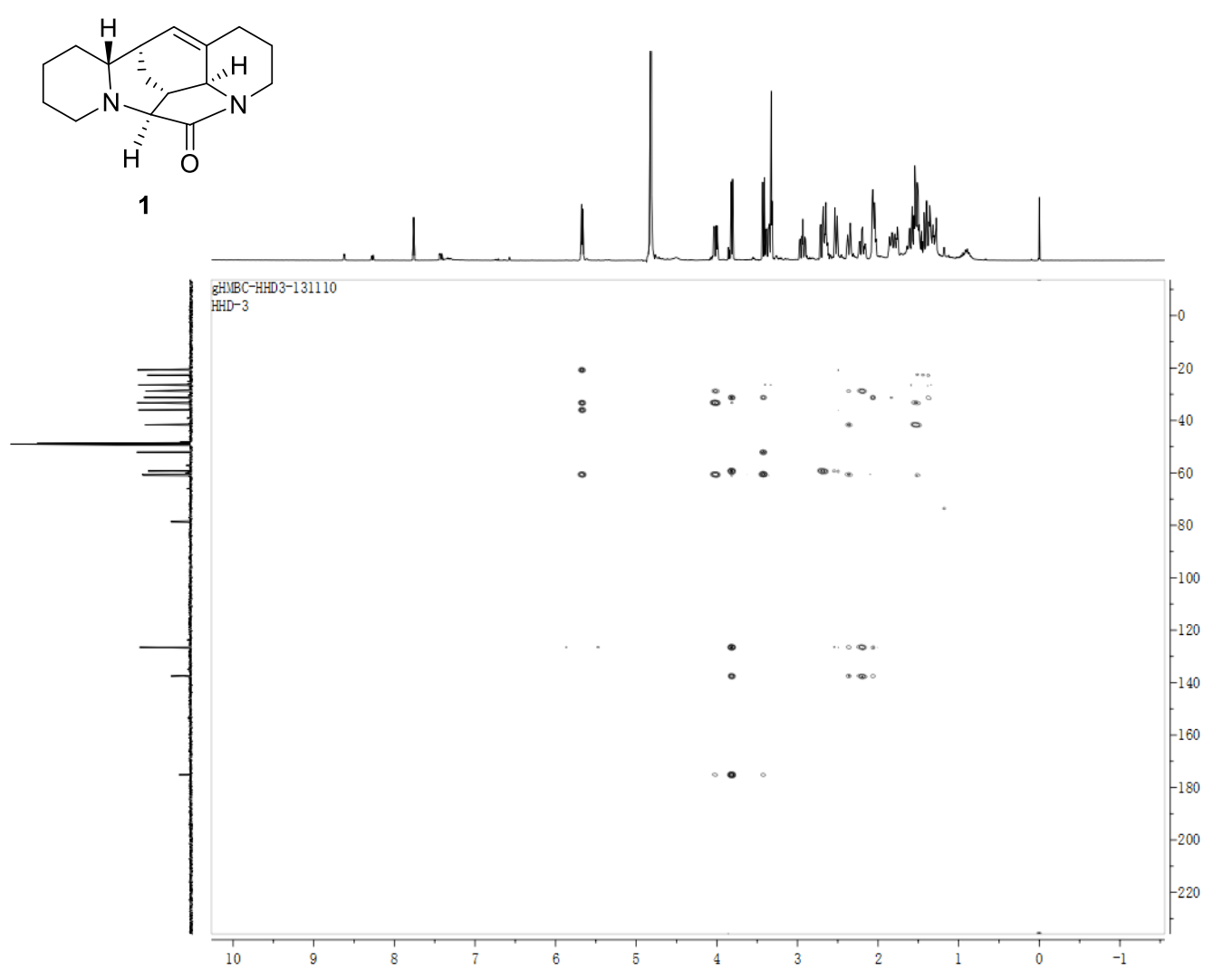

Figure S6. ${ }^{1} \mathrm{H}-{ }^{1} \mathrm{H}$ COSY spectrum of Ochrocephalamines B (1) in $\mathrm{CD}_{3} \mathrm{OD}$.

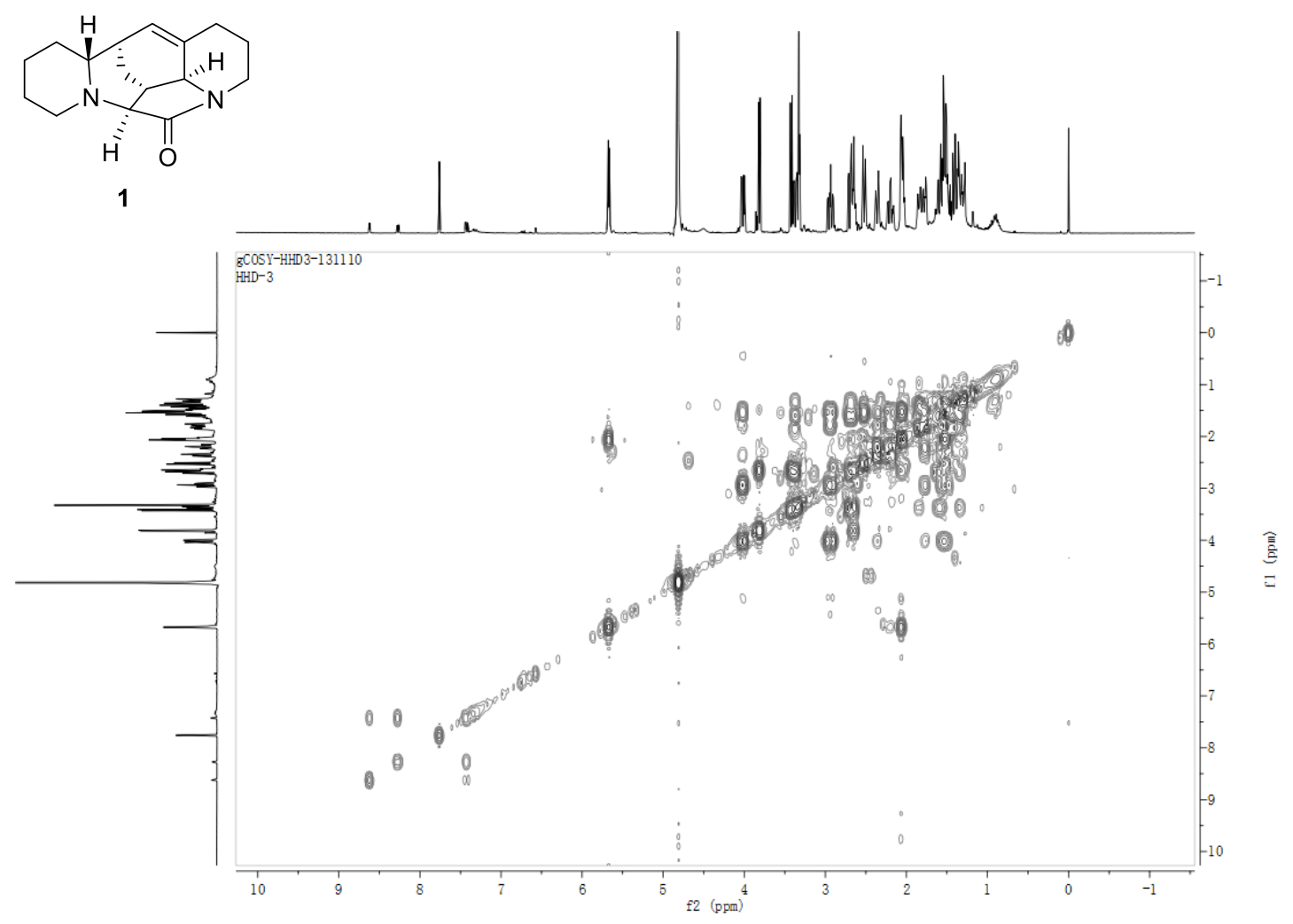


Figure S7. ROESY spectrum of Ochrocephalamines B (1) in $\mathrm{CD}_{3} \mathrm{OD}$.

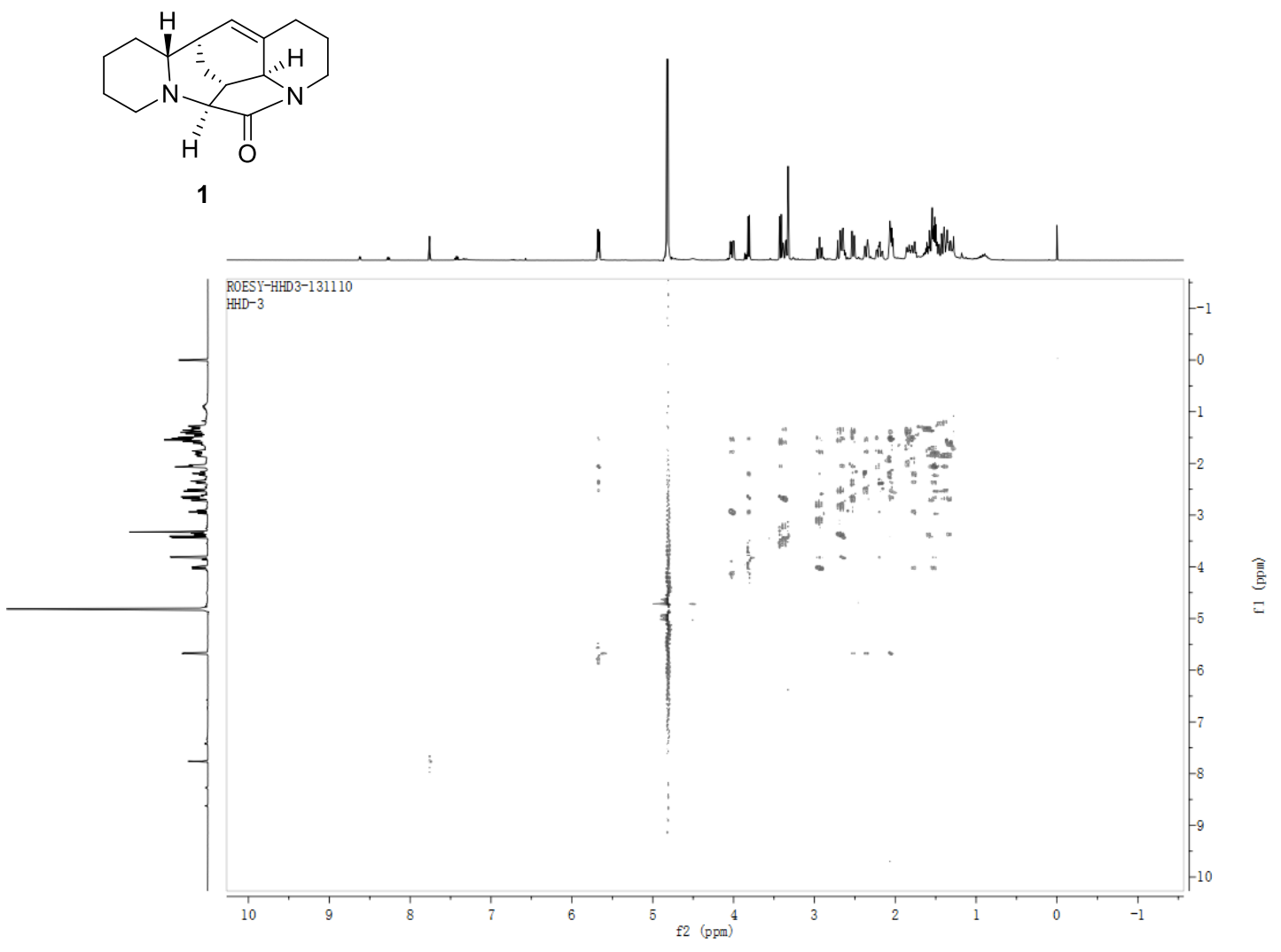

Figure S8. ${ }^{1} \mathrm{H}$ NMR spectrum of Ochrocephalamine C (2).

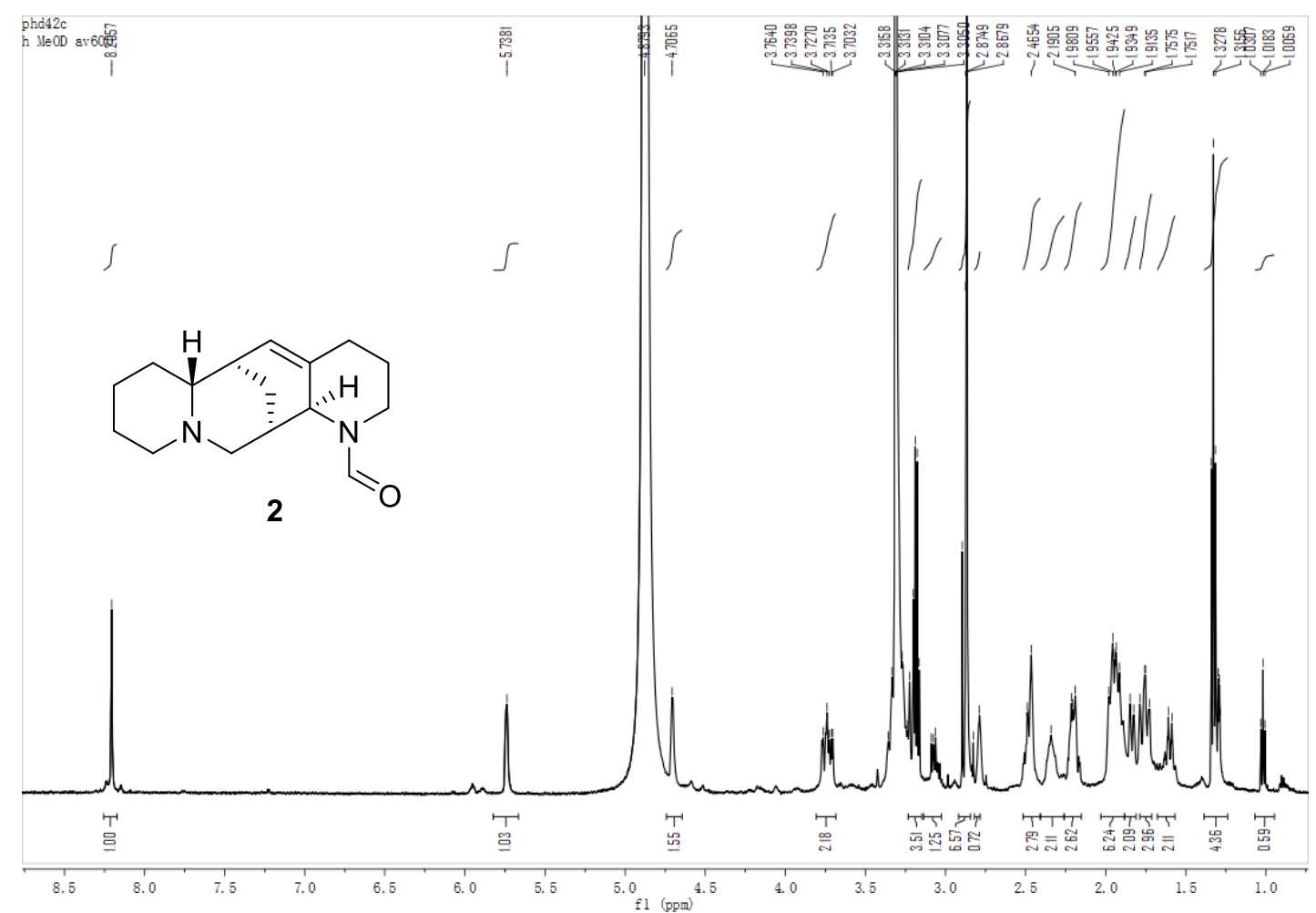


Figure S9. ${ }^{13} \mathrm{C}$ NMR spectrum of Ochrocephalamine C (2).
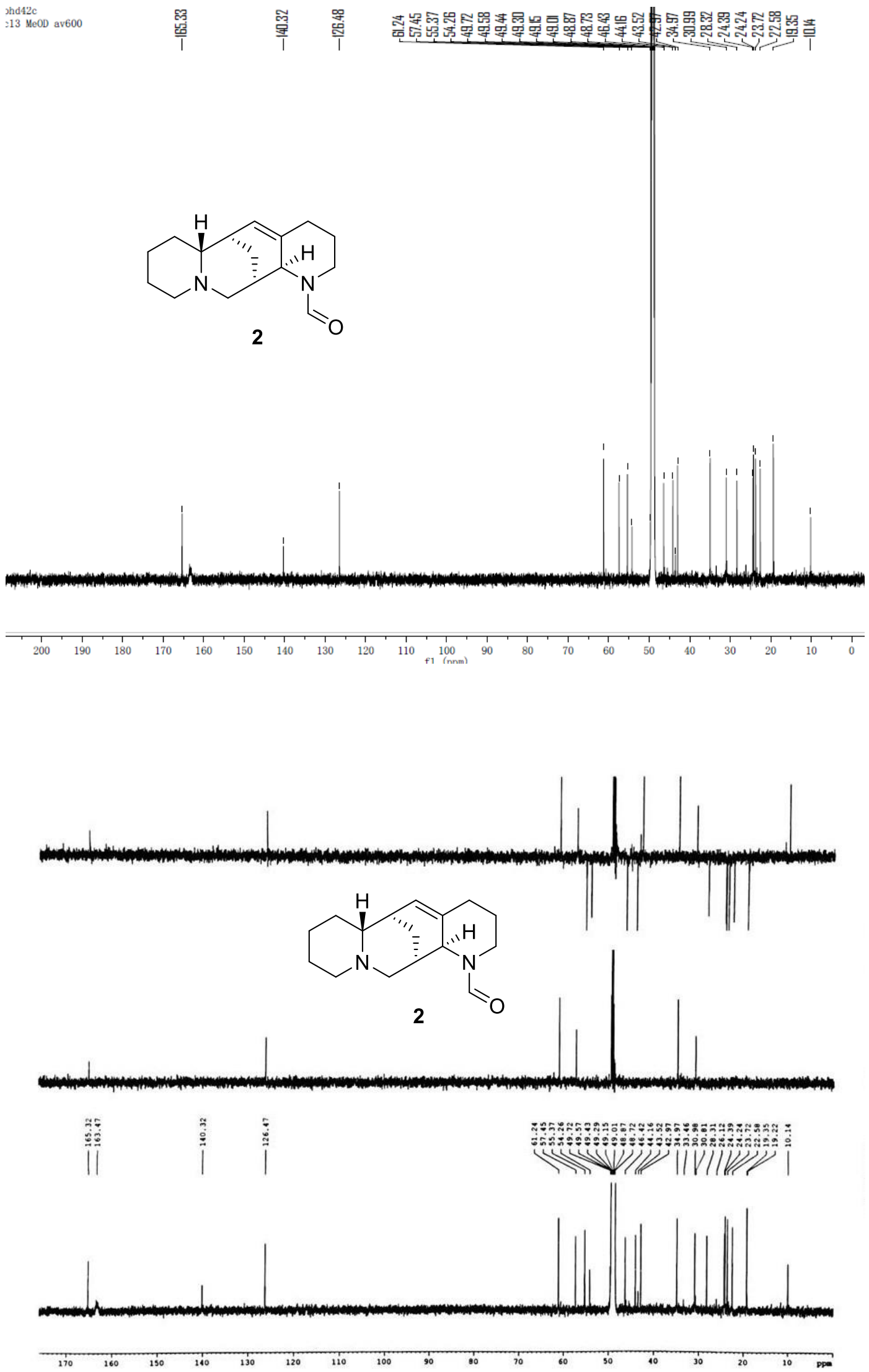
Figure S10. HSQC spectrum of Ochrocephalamine C (2).

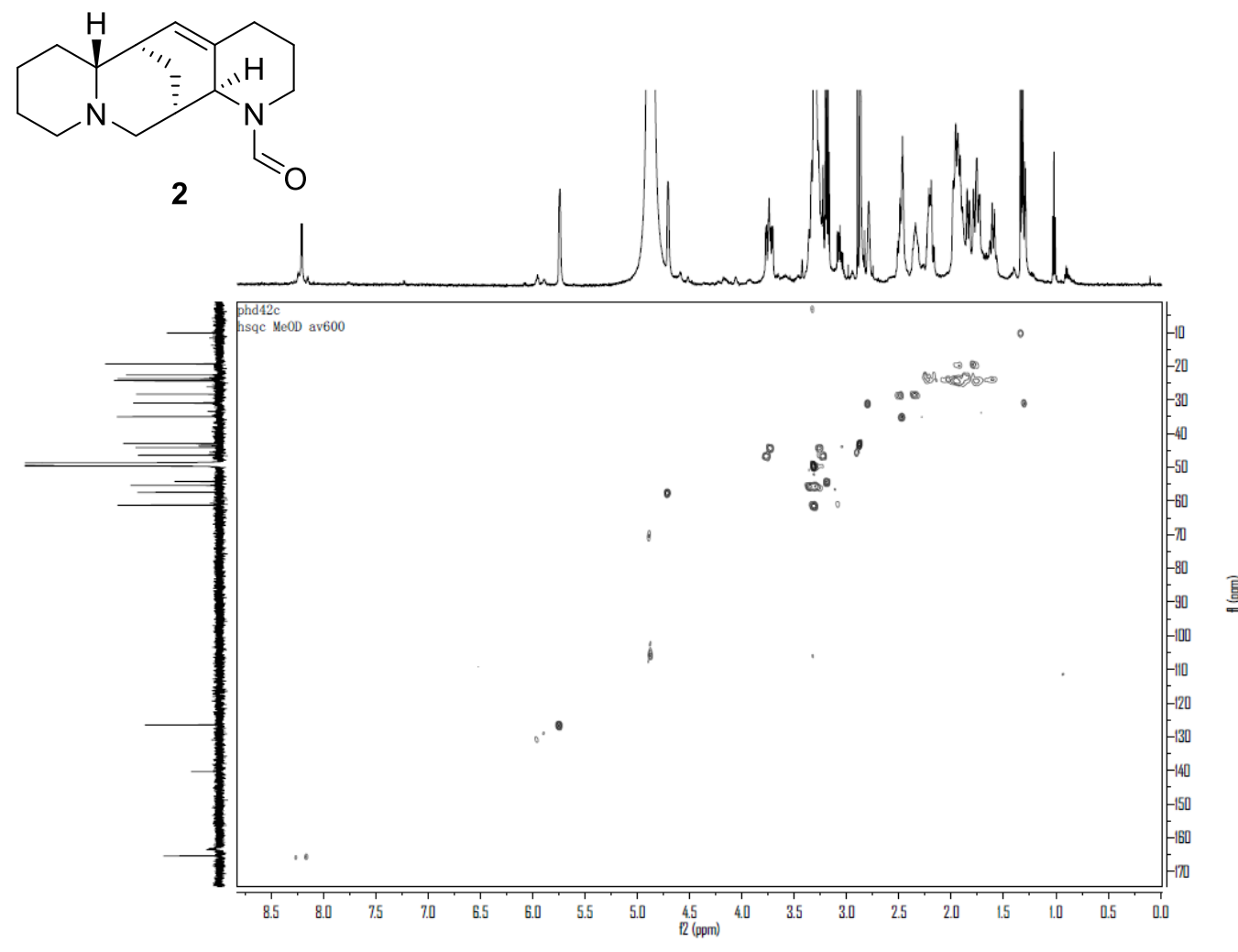

Figure S11. HMBC spectrum of Ochrocephalamine C (2).

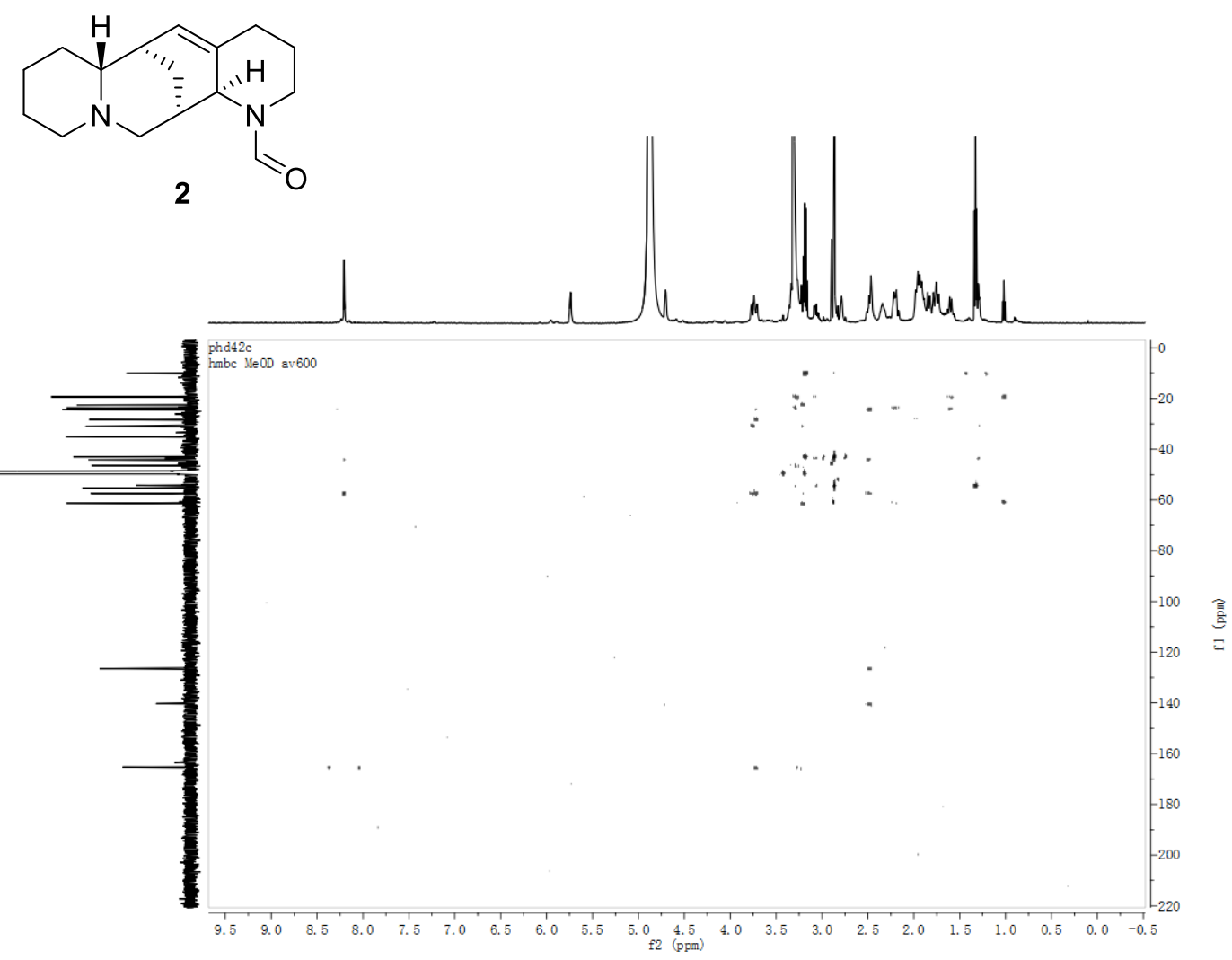

11 
Figure S12. ${ }^{1} \mathrm{H}-{ }^{1} \mathrm{H}$ COSY spectrum of Ochrocephalamine $\mathrm{C}(2)$.

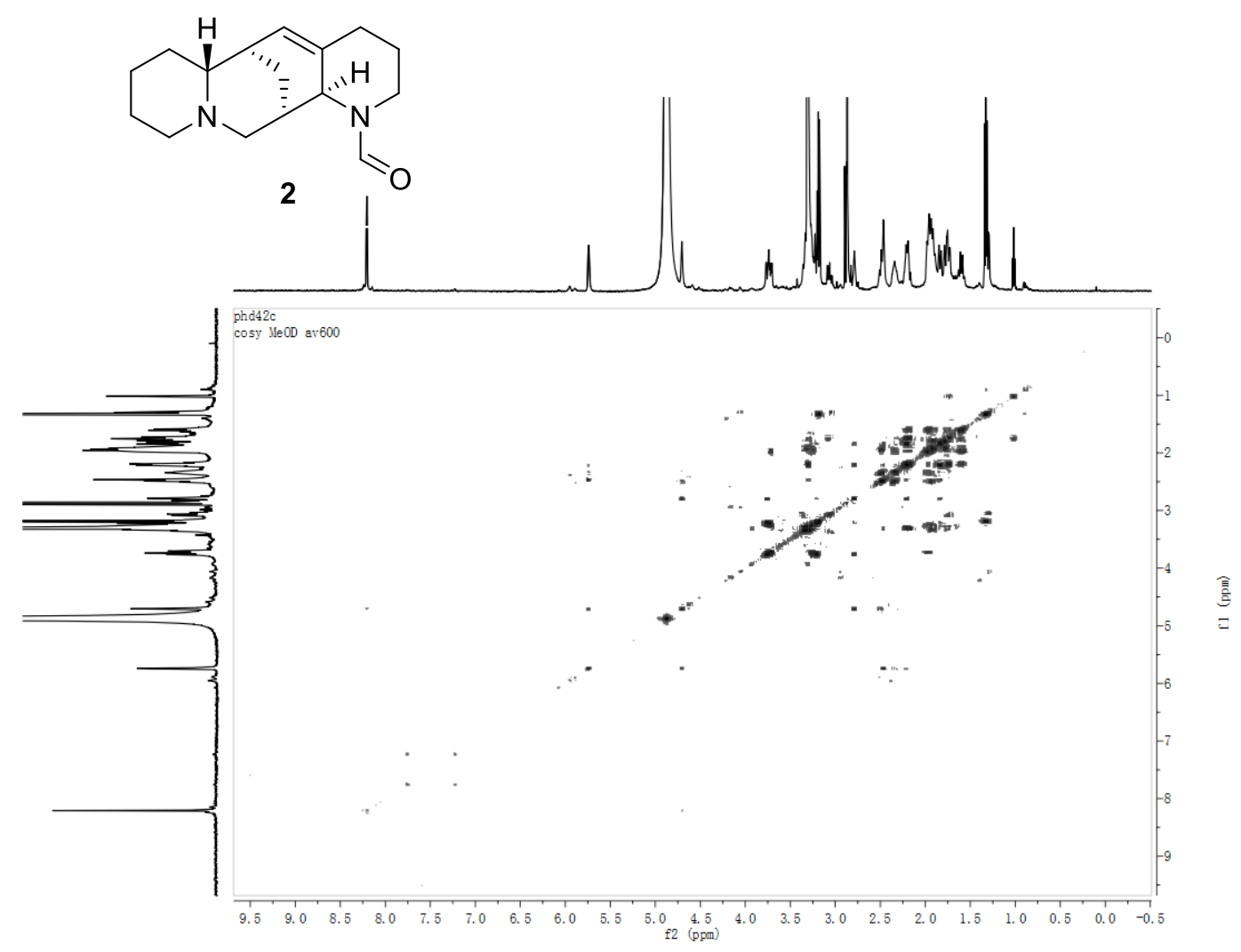

Figure S13. ROESY spectrum of Ochrocephalamine C (2).

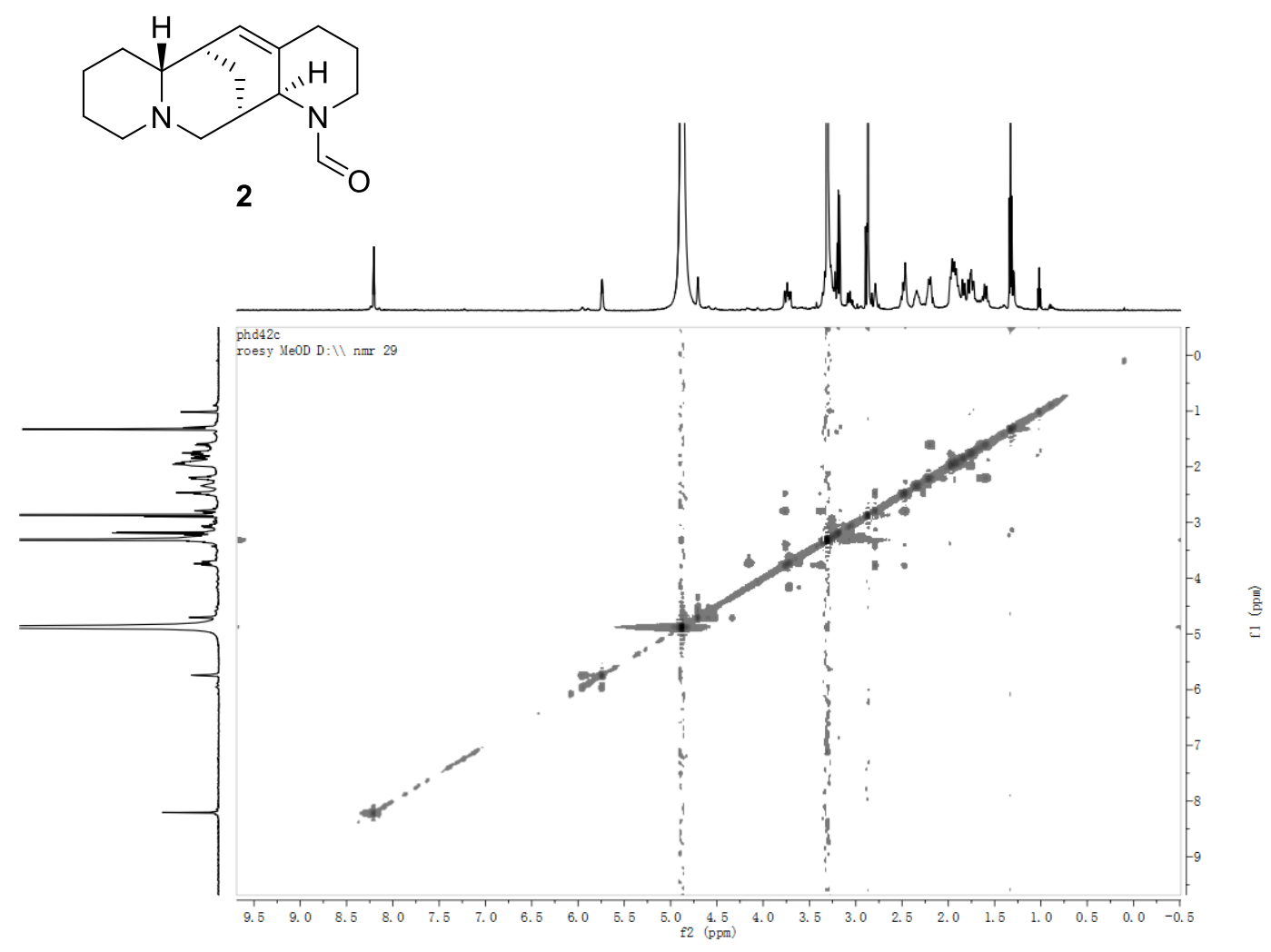


Figure S14. HRESI of Ochrocephalamine D (3)<smiles>ON1CCCC2=C[C@H]3CCCCN3C[C@H]21</smiles>

\section{Qualitative Analysis Report}

\begin{tabular}{|c|c|c|c|}
\hline $\begin{array}{l}\text { Data Filename } \\
\text { Sample Type }\end{array}$ & $\begin{array}{l}\text { 180731ESIA1.d } \\
\text { Sample }\end{array}$ & $\begin{array}{l}\text { Sample Name } \\
\text { Position }\end{array}$ & phd- $42 \mathrm{~b}$ \\
\hline Instrument Name & Aglent G6230 TOF MS & User Name & KIB \\
\hline Acq Method & ESI.m & Acquired Time & $7 / 31 / 2018$ 7:59:27 AM \\
\hline $\begin{array}{l}\text { IRM Calibration Status } \\
\text { Comment }\end{array}$ & Success & DA Method & ESI $\mathrm{m}$ \\
\hline Sample Group & Int & & \\
\hline $\begin{array}{l}\text { Acquisition SW } \\
\text { Version }\end{array}$ & $\begin{array}{l}\text { ies TOF/6500 series } \\
.05 .01 \text { (B5125.2) }\end{array}$ & & \\
\hline
\end{tabular}

User Spectra
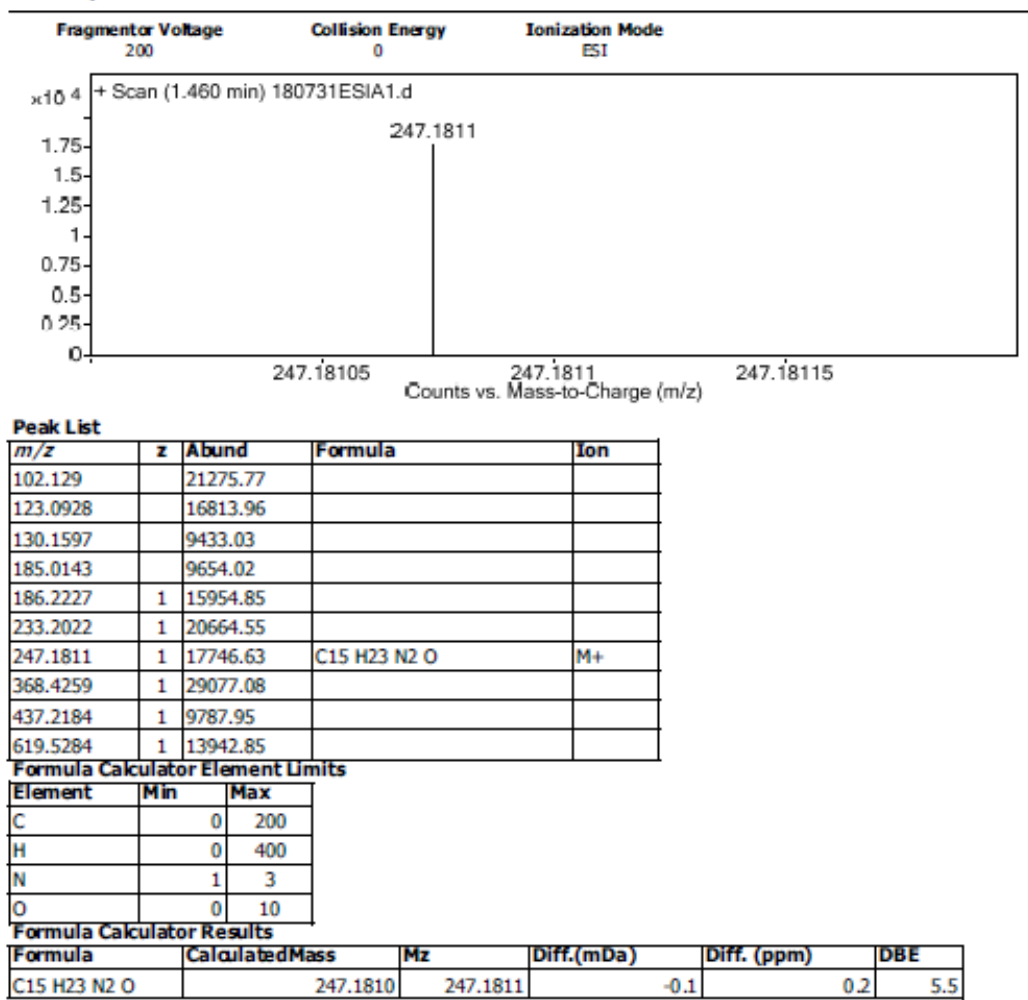

-- End Of Report -- 
Figure S15. ${ }^{1} \mathrm{H}$ NMR spectrum of Ochrocephalamine $\mathrm{D}(\mathbf{3})$ in $\mathrm{CD}_{3} \mathrm{OD}$.

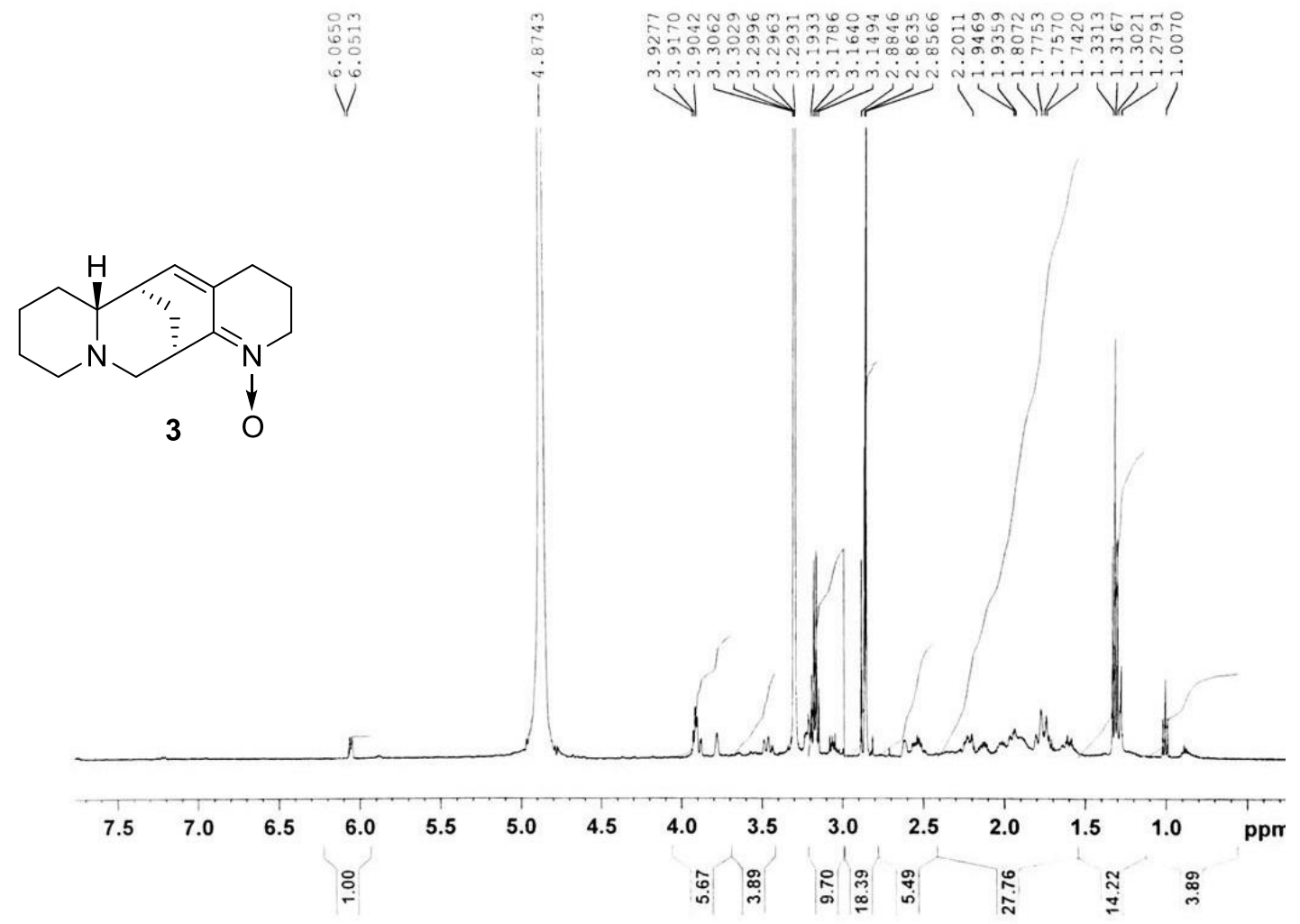

Figure S16. ${ }^{13} \mathrm{C}$ NMR spectrum of Ochrocephalamine $\mathrm{D}(3)$ in $\mathrm{CD}_{3} \mathrm{OD}$.
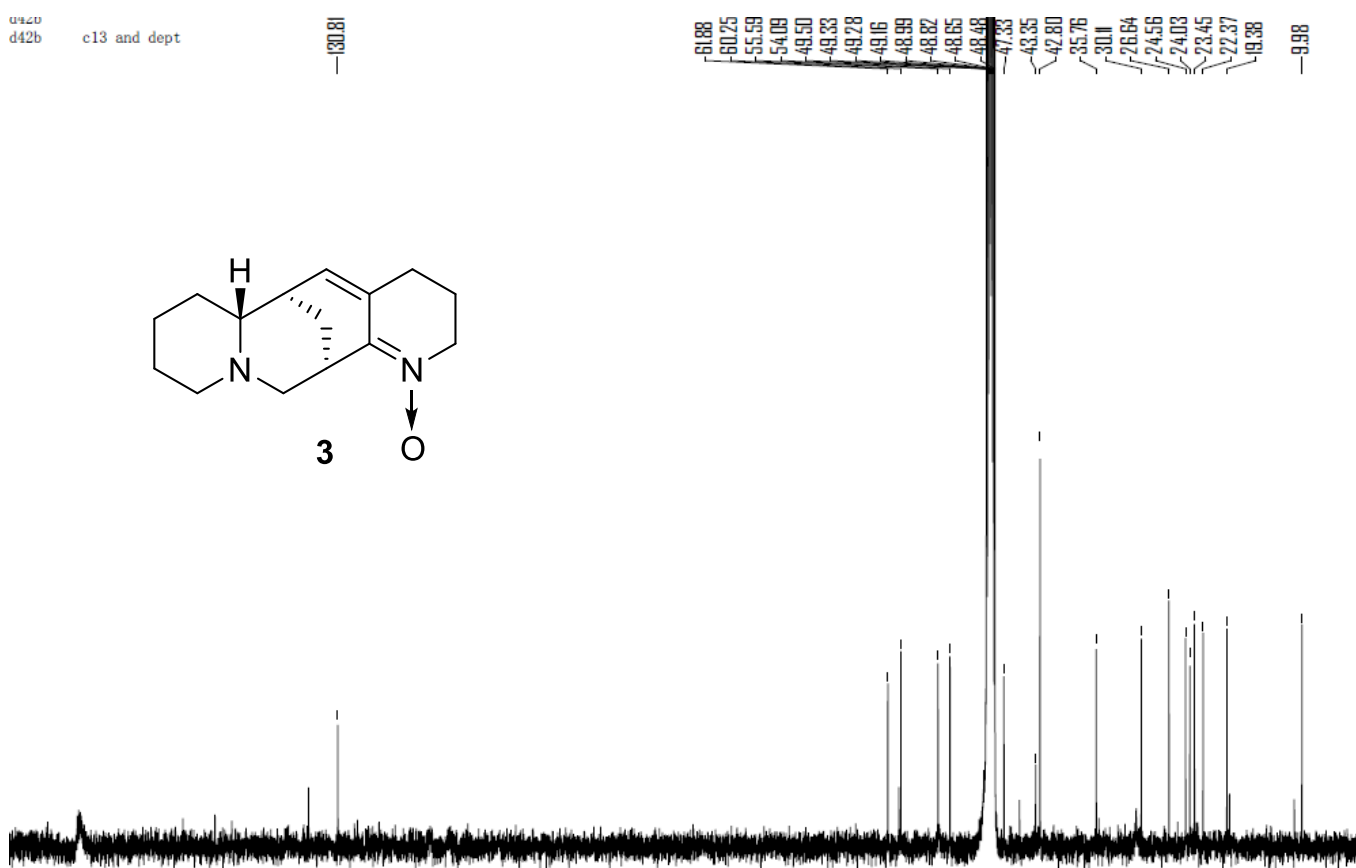

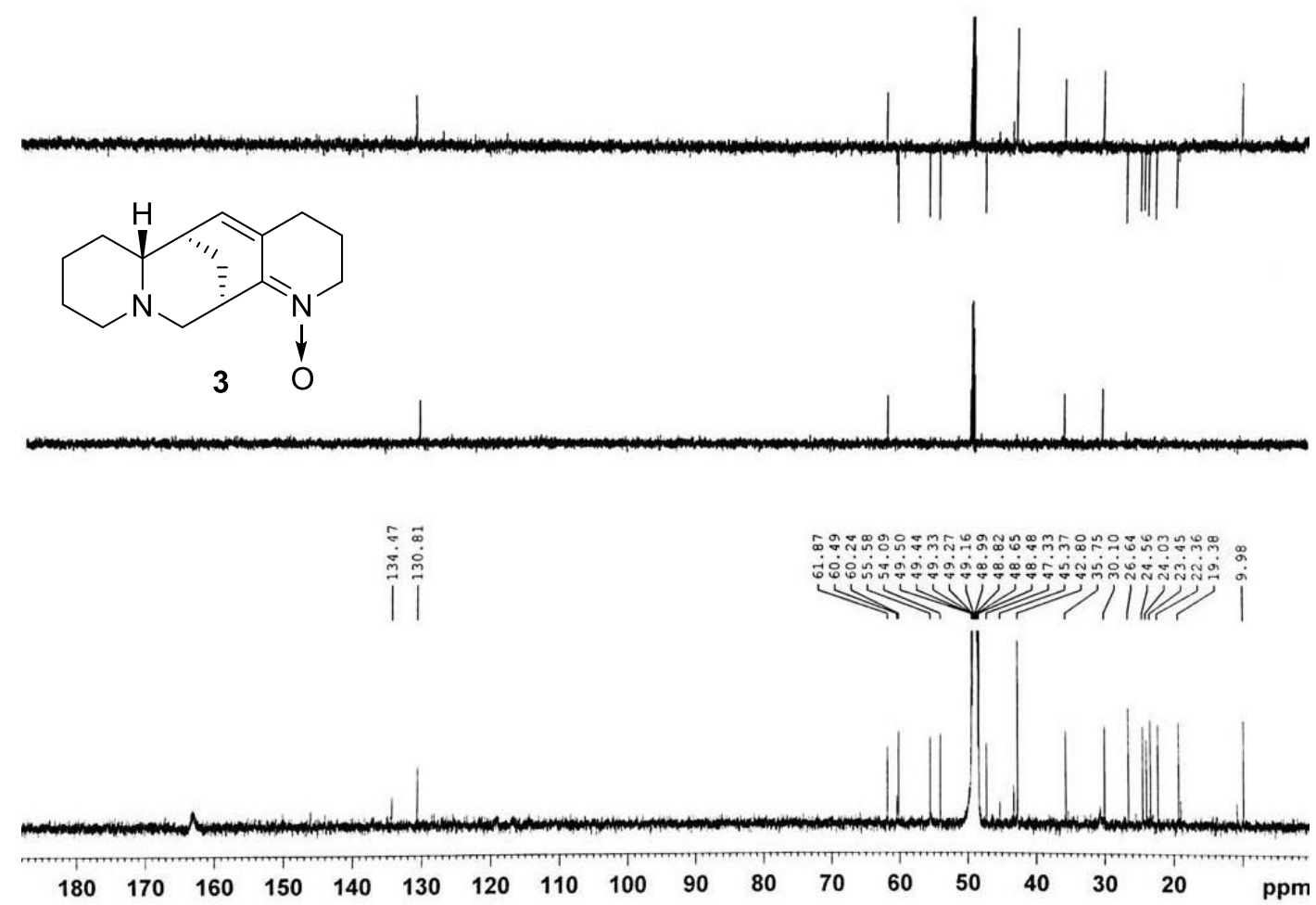

Figure S17. HSQC spectrum of Ochrocephalamine D (3) in $\mathrm{CD}_{3} \mathrm{OD}$.

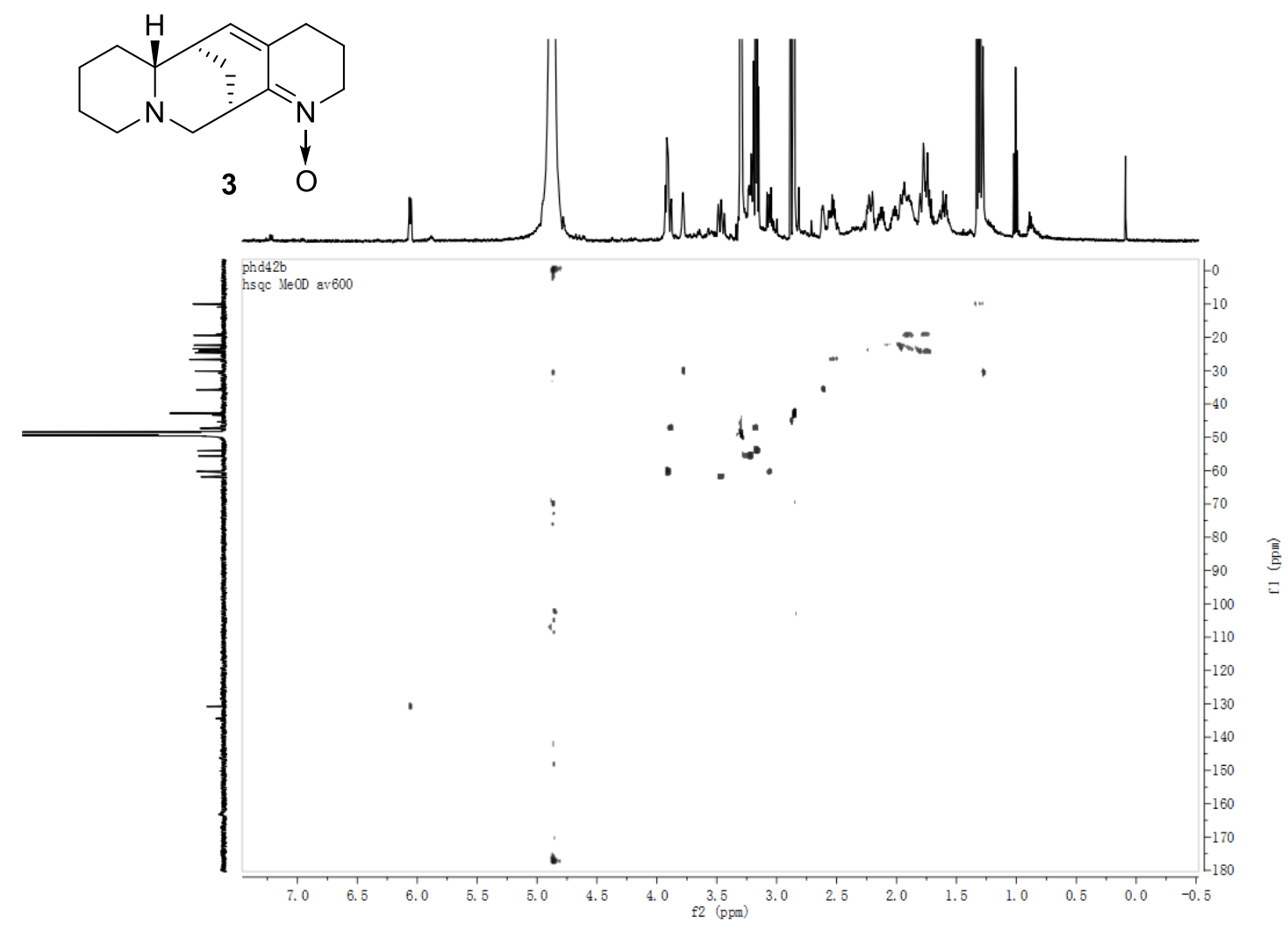


Figure S18. HMBC spectrum of Ochrocephalamine D (3) in $\mathrm{CD}_{3} \mathrm{OD}$.

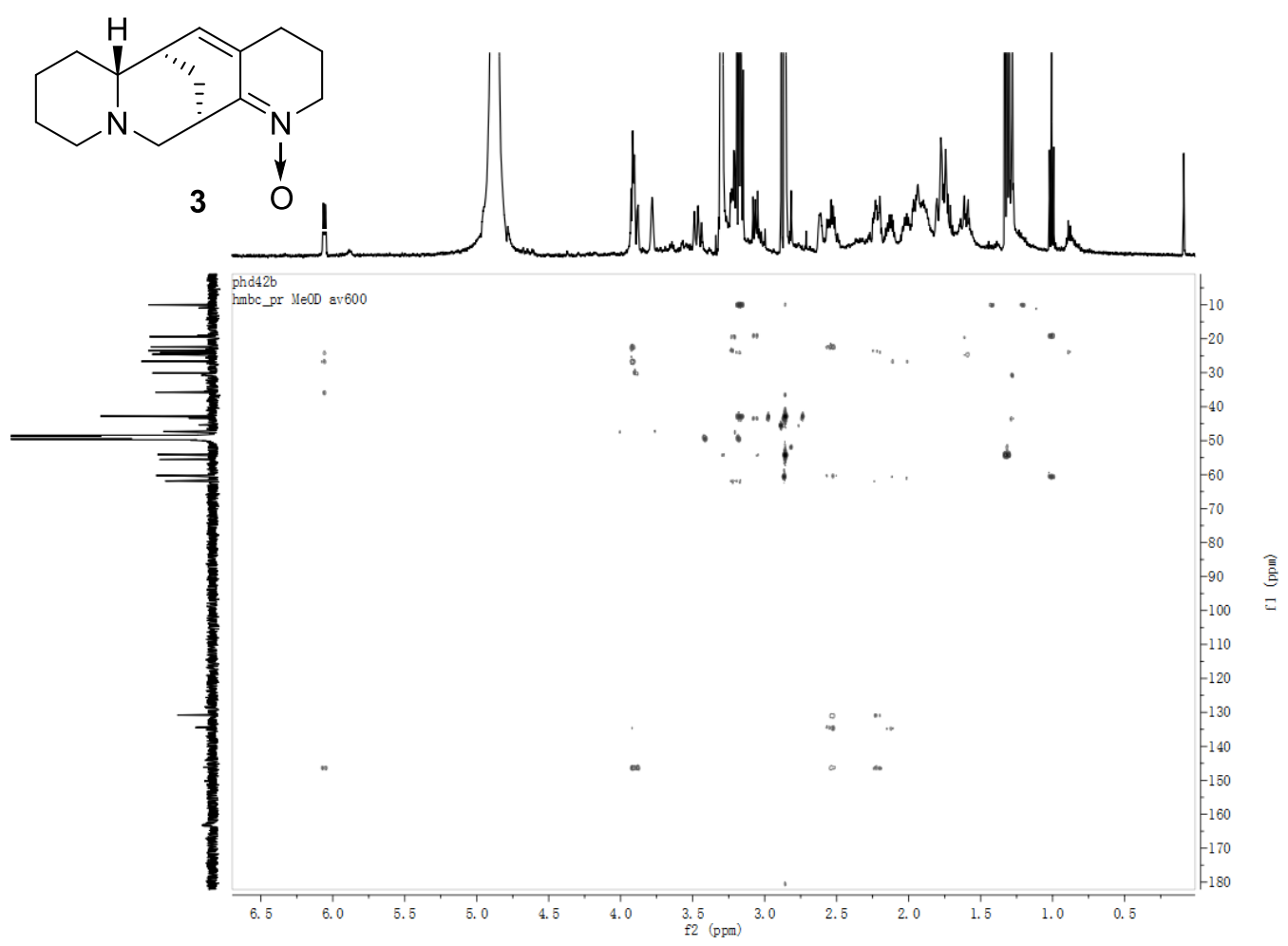

Figure S19. ${ }^{1} \mathrm{H}-{ }^{1} \mathrm{H}$ COSY spectrum of Ochrocephalamine D $(3)$ in $\mathrm{CD}_{3} \mathrm{OD}$.

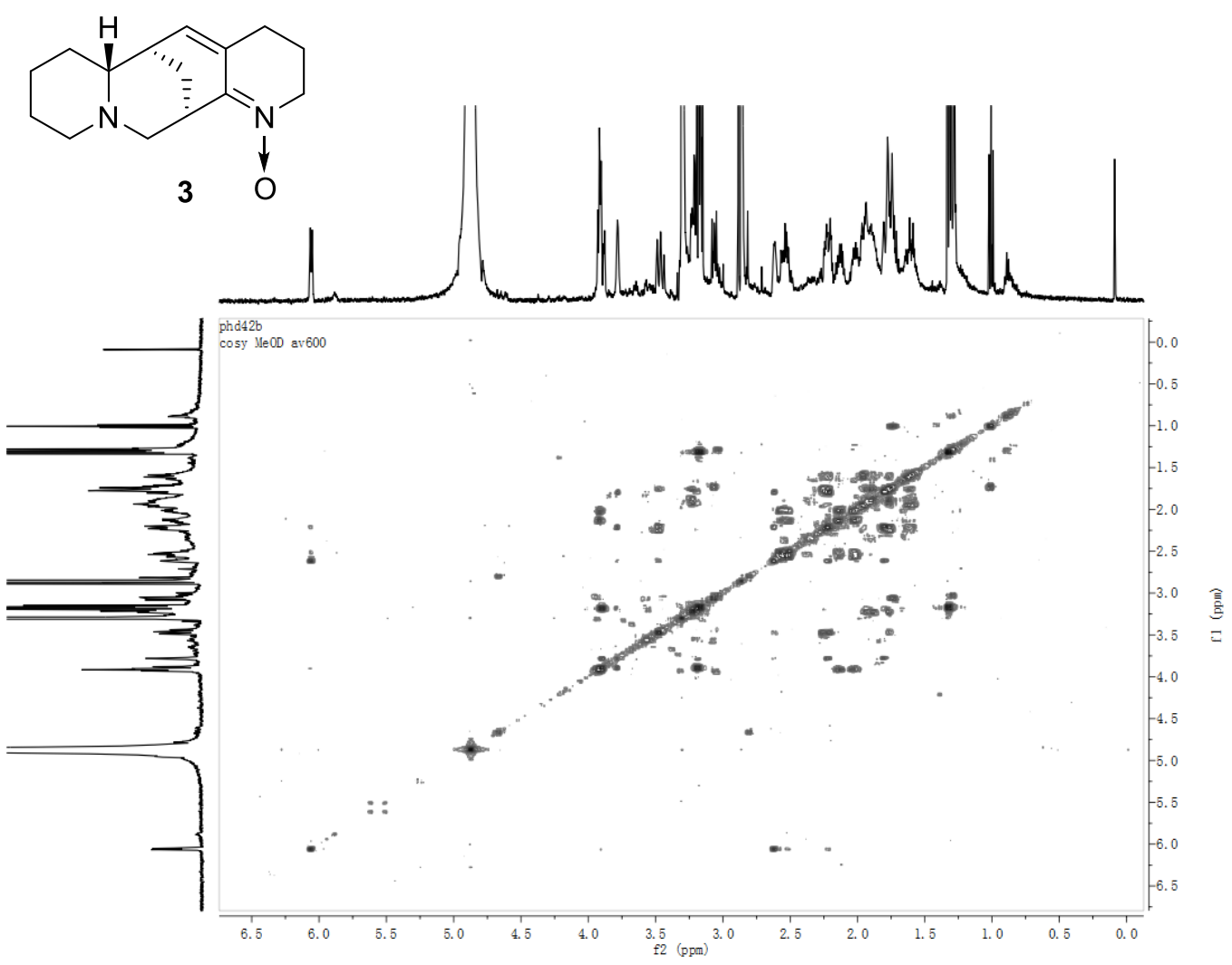


Figure S20. ROESY spectrum of Ochrocephalamine D (3) in $\mathrm{CD}_{3} \mathrm{OD}$.

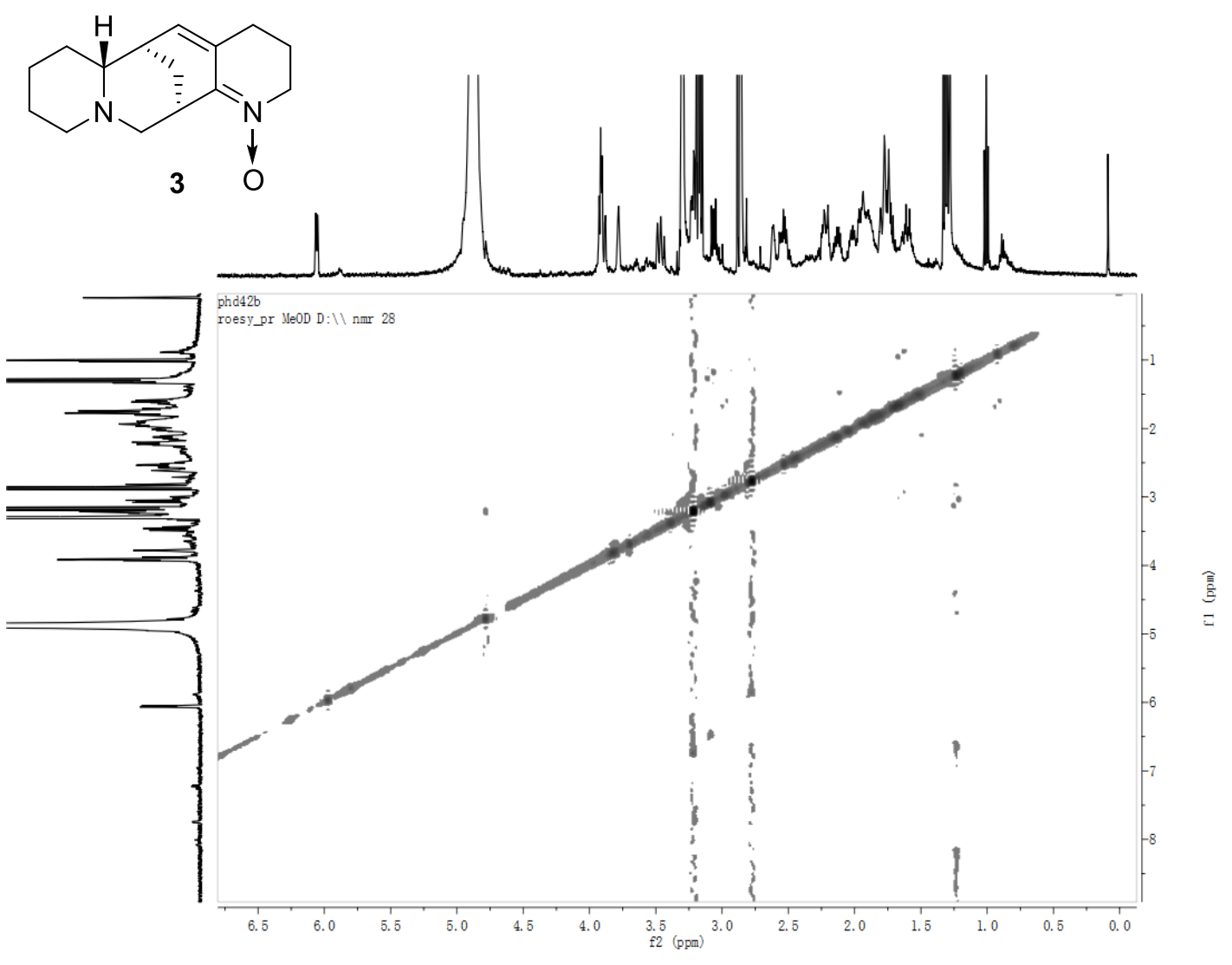

Figure S21. ${ }^{1} \mathrm{H}$ NMR spectrum of Aloperine (4) in $\mathrm{CDCl}_{3}$.

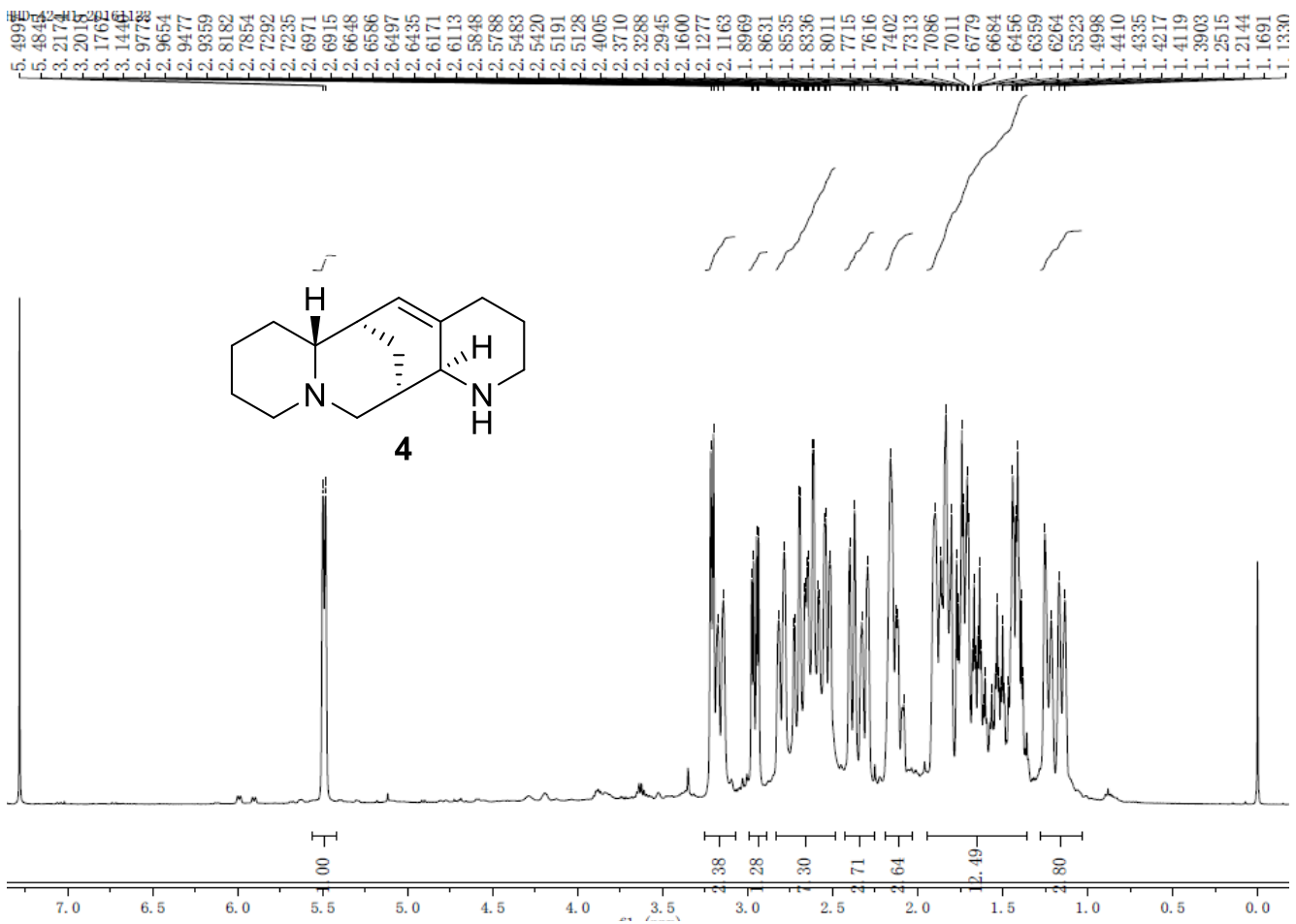


Figure S22. ${ }^{13} \mathrm{C}$ NMR spectrum of Aloperine (4) in $\mathrm{CDCl}_{3}$.
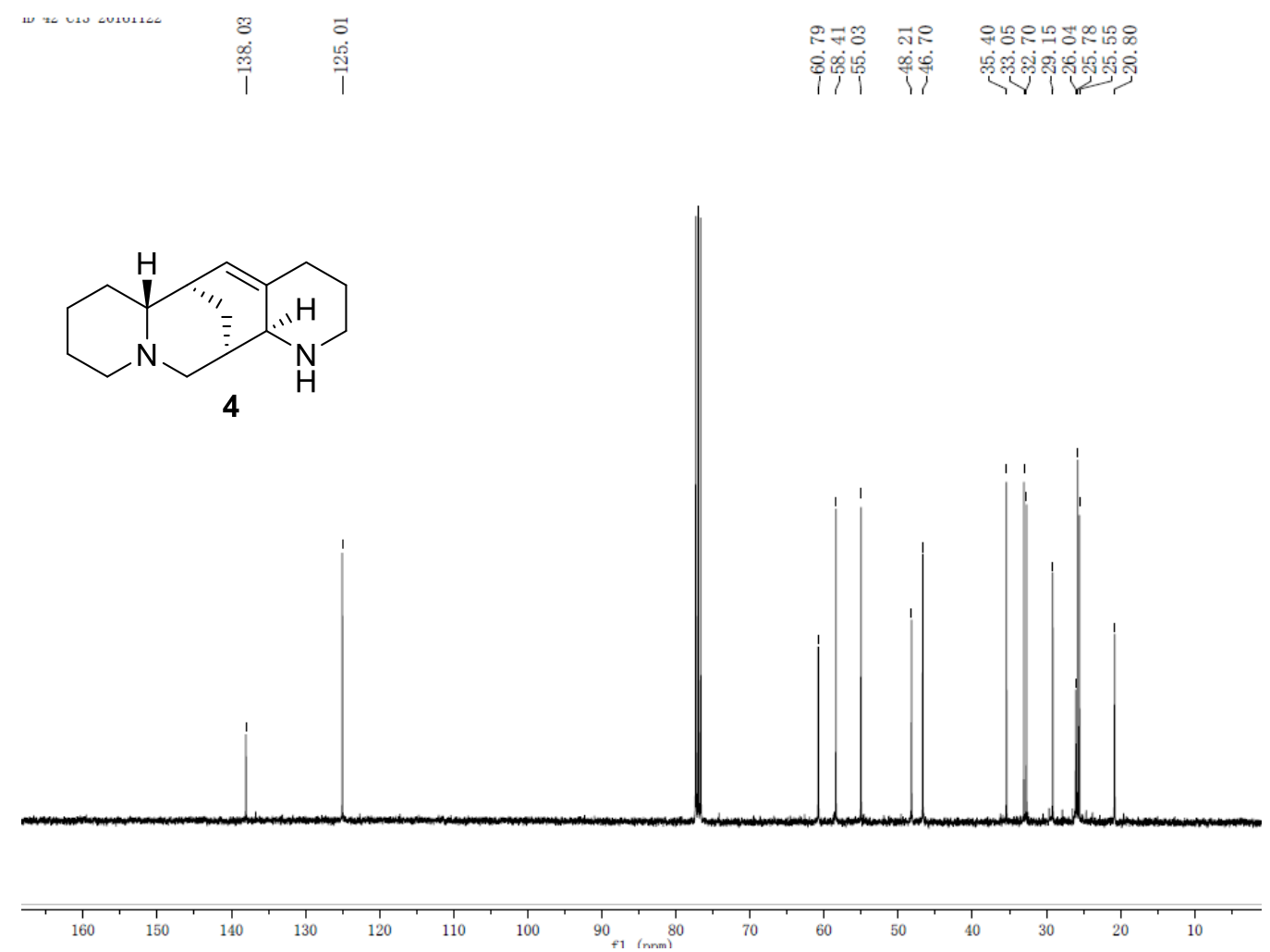

HHD-42-DEPT-20161114

new experiment

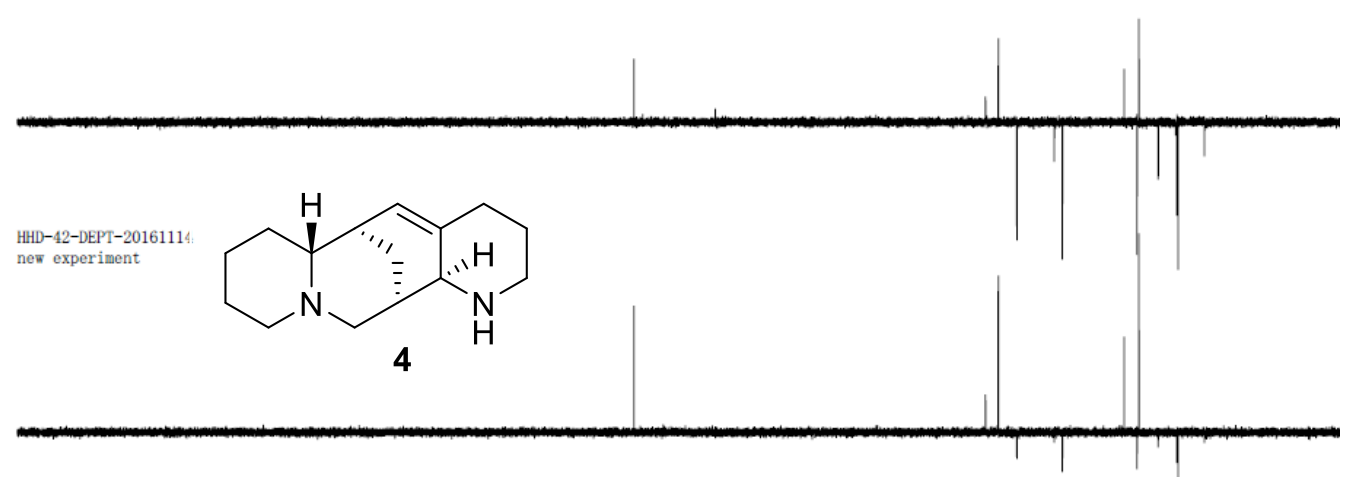

HHD-42-DEPT-20161114

new experiment 
S23. Physical data of 1-3.

Ochrocephalamine B (1): white solid; $[\alpha]^{23.4} \mathrm{D}=-77.5(c 0.10, \mathrm{MeOH}) ; \mathrm{ECD}(c, 0.011, \mathrm{MeOH})$ $\lambda_{\max }(\Delta \varepsilon) 244$ (+0.36), $207(-27.20) \mathrm{nm} ; \mathrm{UV}(\mathrm{MeOH}) \lambda_{\max }(\log \varepsilon) 203 \mathrm{~nm}$ (4.07); IR (KBr) $v_{\max }$ 2927, 2852, 1689, 1440, $1417 \mathrm{~cm}^{-1} ;{ }^{1} \mathrm{H}$ and ${ }^{13} \mathrm{C}$ NMR data (Table 1); HREIMS $\mathrm{m} / z 258.1730[\mathrm{M}]^{+}$, (calcd for $\mathrm{C}_{16} \mathrm{H}_{22} \mathrm{~N}_{2} \mathrm{O}, 258.1732$ )

Ochrocephalamine C (2): white solid; $[\alpha]^{24.9} \mathrm{D}=+41.7(c 0.35, \mathrm{MeOH}) ; \mathrm{ECD}(c, 0.032, \mathrm{MeOH})$ $\lambda_{\max }(\Delta \varepsilon) 292(+0.56), 225(-0.84), 200(+5.73) \mathrm{nm} ; \mathrm{UV}(\mathrm{MeOH}) \lambda_{\max }(\log \varepsilon) 206 \mathrm{~nm}(3.53), 295$ nm (2.72); ${ }^{1} \mathrm{H}$ and ${ }^{13} \mathrm{C}$ NMR data (Table 1); ESIMS $m / z 261[\mathrm{M}+\mathrm{H}]^{+}$; HRESIMS $m / z 261.1961$ $[\mathrm{M}+\mathrm{H}]^{+}$(calcd for $\left.\mathrm{C}_{16} \mathrm{H}_{24} \mathrm{~N}_{2} \mathrm{O}, 261.1967\right)$.

Ochrocephalamine D (3): a light yellow solid; $[\alpha]^{24.8} \mathrm{D}=+21.6(c 0.17, \mathrm{MeOH}) ; \mathrm{ECD}(c, 0.075$, $\mathrm{MeOH}) \lambda_{\max }(\Delta \varepsilon) 310(-0.24), 281(+1.16), 210(+0.41) \mathrm{nm} ; \mathrm{UV}(\mathrm{MeOH}) \lambda_{\max }(\log \varepsilon) 206 \mathrm{~nm}$ (3.11), $286 \mathrm{~nm}$ (3.23); ${ }^{1} \mathrm{H}$ and ${ }^{13} \mathrm{C}$ NMR data (Table 1); ESIMS $m / z, 247[\mathrm{M}+\mathrm{H}]^{+} ;$HRESIMS $\mathrm{m} / z$ $247.1811[\mathrm{M}+\mathrm{H}]^{+}\left(\right.$calcd for $\left.\mathrm{C}_{15} \mathrm{H}_{22} \mathrm{~N}_{2} \mathrm{O}, 247.1810\right)$. 
S24. ECD spectra calculation of $\mathbf{1 - 3}$

Computational methods: The CONFLEX ${ }^{[1,2]}$ searches based on molecular mechanicswith MMFF94S force fields were performed for compounds, which gave 10 stable conformers. Selected conformers with distributions higher than $1 \%$ were further optimized by the DFT (density functional theory) method at the B3LYP/6-311+g (d, p) level in Gaussian 16 program package. ${ }^{[3]}$ The ECD of the conformer of selected conformerswas then calculated by the TDDFT method at the cam-b3lyp/tzvp levels with the PCM model in methanol solution. The calculated ECD curve was generated using SpecDis 1.71. ${ }^{[4]}$

\section{References}

[1] Goto, H.; Osawa, E.; J. Am. Chem. Soc.1989, 111, 8950-8951.

[2] Goto, H.; Osawa, E.; J. Chem. Soc., Perkin Trans. 2, 1993, 187-198.

[3] Frisch, M. J.; Trucks, G. W.; Schlegel, H. B.; Scuseria, G. E.; Robb,M. A.; Cheeseman, J. R.; Montgomery, Jr., J. A.; Vreven, T.; Kudin, K. N.;Burant, J. C.; Millam, J. M.; Iyengar, S. S.; Tomasi, J.; Barone, V.;Mennucci, B.; Cossi, M.; Scalmani, G.; Rega, N.; Petersson, G. A.;Nakatsuji, H.; Hada, M.; Ehara, M.; Toyota, K.; Fukuda, R.; Hasegawa, J.;Ishida, M.; Nakajima, T.; Honda, Y.; Kitao, O.; Nakai, H.; Klene, M.; Li,X.; Knox, J. E.; Hratchian, H. P.; Cross, J. B.; Bakken, V.; Adamo, C.;Jaramillo, J.; Gomperts, R.; Stratmann, R. E.; Yazyev, O.; Austin, A. J.;Cammi, R.; Pomelli, C.; Ochterski, J. W.; Ayala, P. Y.; Morokuma, K.;Voth, G. A.; Salvador, P.; Dannenberg, J. J.; Zakrzewski, V. G.; Dapprich,S.; Daniels, A. D.; Strain, M. C.; Farkas, O.; Malick, D. K.; Rabuck, A. D.;Raghavachari, K.; Foresman, J. B.; Ortiz, J. V.; Cui, Q.; Baboul, A. G.;Clifford, S.; Cioslowski, J.; Stefanov, B. B.; Liu, G.; Liashenko, A.; Piskorz,P.; Komaromi, I.; Martin, R. L.; Fox, D. J.; Keith, T.; Al-Laham, M. A.;Peng, C. Y.; Nanayakkara, A.; Challacombe, M.; Gill, P. M. W.; Johnson,B.; Chen, W.; Wong, M. W.; Gonzalez, C.; Pople, J. A. Gaussian 03,revision D.01; Gaussian, Inc.: Wallingford, CT, 2005.

[4] Bruhn, T.; Hemberger, Y.; Schaumlöffel, A.; Bringmann, G. Spec Dis, version 1.51, University of Würzburg, Germany, 2010. 
1. ECD spectra calculation of 1

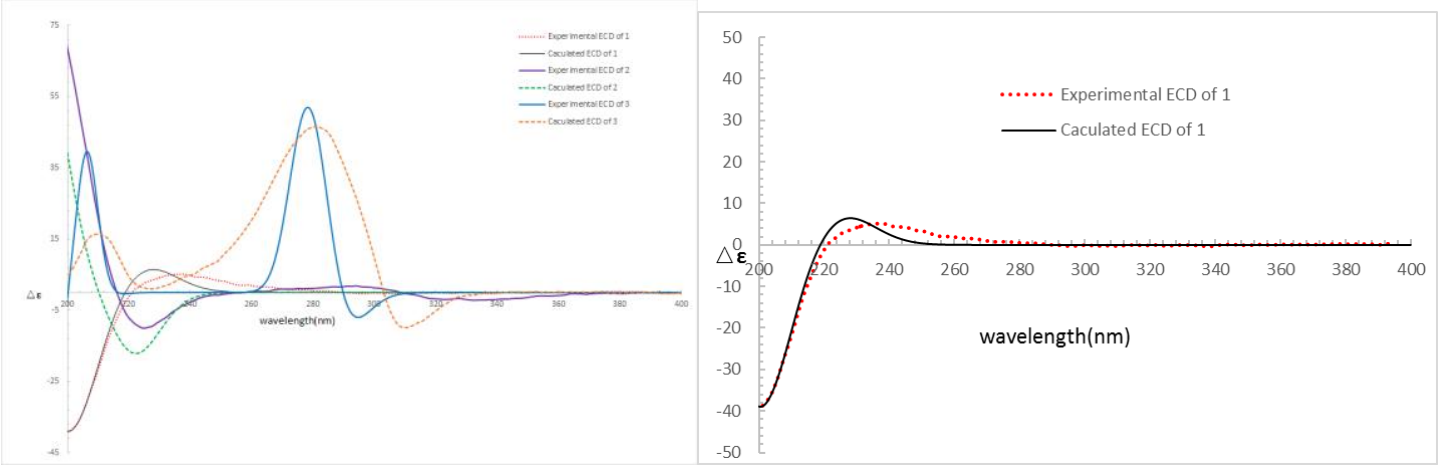

b3lyp/6-311 $+g(d, p)$ optimized lowest energy 3D conformer of 1

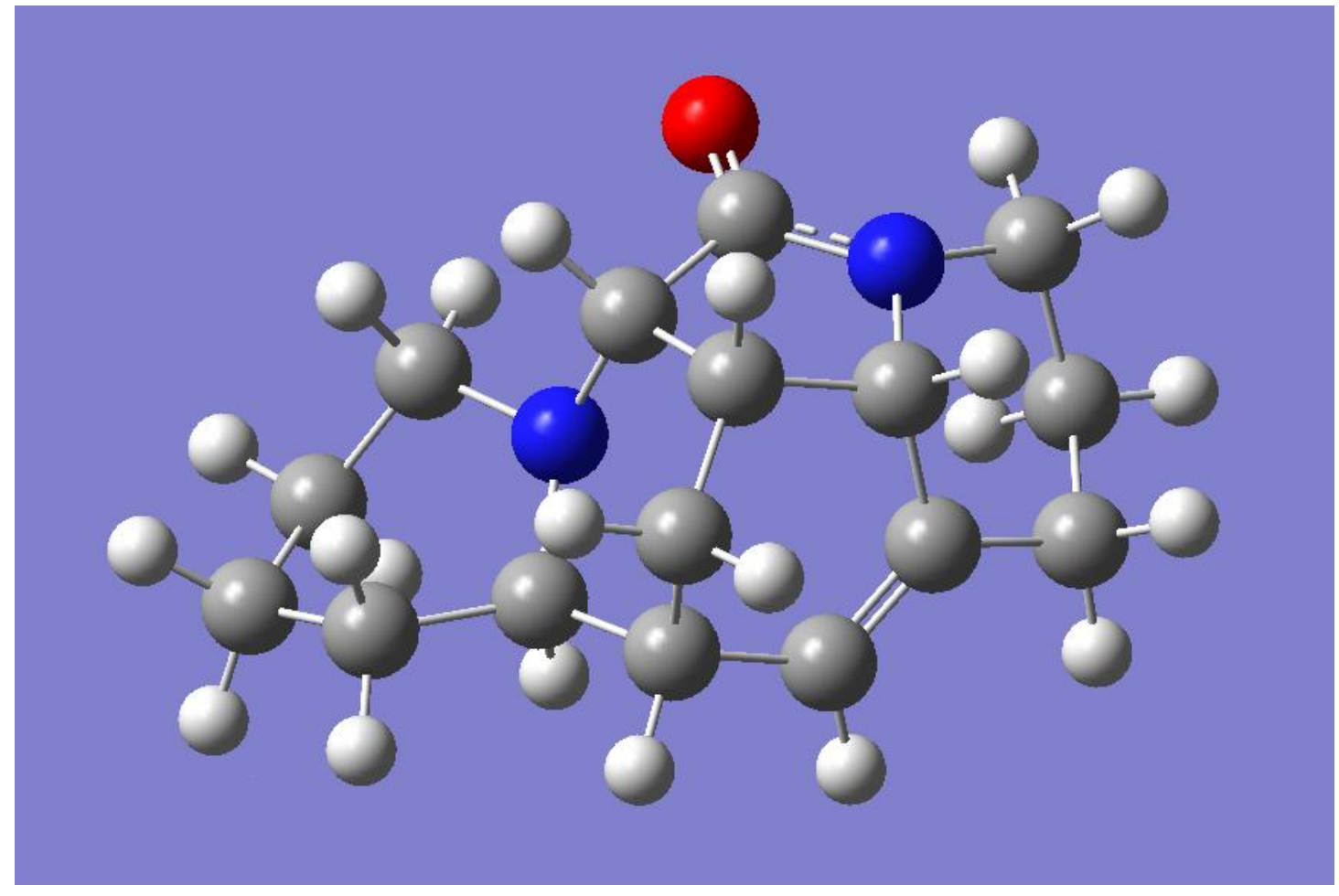

Absolute confirguration of 1

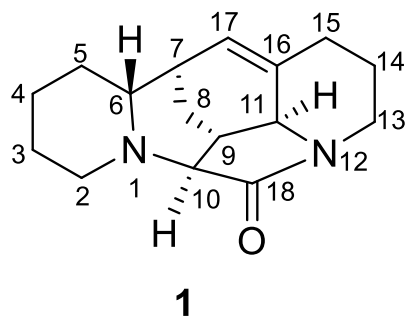

Computational methods for ECD of compound 1 
$\mathrm{td}=(50-50$, nstates $=50)$ cam-b3lyp/tzvp scrf $=($ solvent $=$ methanol $)$

Input orientation:

$\begin{array}{lccccc}\text { Center } & \text { Atomic } & \text { Atomic } & \text { Coordinates (Angstroms) } & \\ \text { Number } & \text { Number } & \text { Type } & X & Y & Z\end{array}$

$\begin{array}{rrrrrr}-1 & 6 & 0 & -2.211870 & 1.522715 & 0.189345 \\ 2 & 6 & 0 & -3.065167 & 1.381752 & -1.069686 \\ 3 & 6 & 0 & -3.717936 & -0.001395 & -1.132442 \\ 4 & 6 & 0 & -2.653246 & -1.089273 & -0.967247 \\ 5 & 6 & 0 & -1.823872 & -0.888243 & 0.309953 \\ 6 & 7 & 0 & -1.215019 & 0.449451 & 0.294015 \\ 7 & 6 & 0 & 0.639585 & -0.436375 & 1.794939 \\ 8 & 6 & 0 & -0.215620 & 0.759626 & 1.336961 \\ 9 & 6 & 0 & 1.456431 & -1.297774 & -0.480358 \\ 10 & 6 & 0 & 1.775583 & -0.491310 & 0.761635 \\ 11 & 6 & 0 & 2.474403 & -1.119930 & -1.599479 \\ 12 & 6 & 0 & 3.502713 & -0.014786 & -1.274726 \\ 13 & 6 & 0 & 2.856368 & 1.261633 & -0.717130 \\ 14 & 7 & 0 & 1.935981 & 0.915139 & 0.372045 \\ 15 & 6 & 0 & 0.828594 & 1.672993 & 0.650113 \\ 16 & 8 & 0 & 0.682240 & 2.839866 & 0.329229 \\ 17 & 6 & 0 & -0.099367 & -1.765578 & 1.867120 \\ 18 & 6 & 0 & -0.746678 & -1.989812 & 0.498808 \\ 19 & 6 & 0 & 0.305708 & -1.964846 & -0.592232 \\ 20 & 1 & 0 & 2.699957 & -0.854378 & 1.226902 \\ 21 & 1 & 0 & 1.071735 & -0.173277 & 2.764765 \\ 22 & 1 & 0 & -0.681339 & 1.266366 & 2.195159 \\ 23 & 1 & 0 & -2.518202 & -0.984818 & 1.171527 \\ 24 & 1 & 0 & -1.681885 & 2.475370 & 0.180774 \\ 25 & 1 & 0 & -2.869973 & 1.518646 & 1.082200 \\ 26 & 1 & 0 & -3.823158 & 2.171647 & -1.080872 \\ 27 & 1 & 0 & -2.427361 & 1.531602 & -1.947729 \\ 28 & 1 & 0 & -4.257856 & -0.136096 & -2.075197 \\ 29 & 1 & 0 & -4.460579 & -0.091973 & -0.329047 \\ 30 & 1 & 0 & -3.118070 & -2.081001 & -0.932131 \\ 31 & 1 & -1.980288 & -1.071871 & -1.830977 \\ 32 & 1 & 0 & -0.008525 & -2.057955 & -1.788095 \\ 33 & 1 & 0 & -0.071350 & 0.242357 & -2.172093 \\ 36 & 1 & 0 & 1.955661 & -0.361109\end{array}$




$\begin{array}{lllccc}37 & 1 & 0 & 2.285308 & 1.785713 & -1.490750 \\ 38 & 1 & 0 & -0.861087 & -1.744831 & 2.653188 \\ 39 & 1 & 0 & 0.600054 & -2.572617 & 2.108726 \\ 40 & 1 & 0 & -1.269212 & -2.952303 & 0.480528 \\ 41 & 1 & 0 & 0.070148 & -2.468161 & -1.527343\end{array}$

\section{ECD spectra calculation of 2}

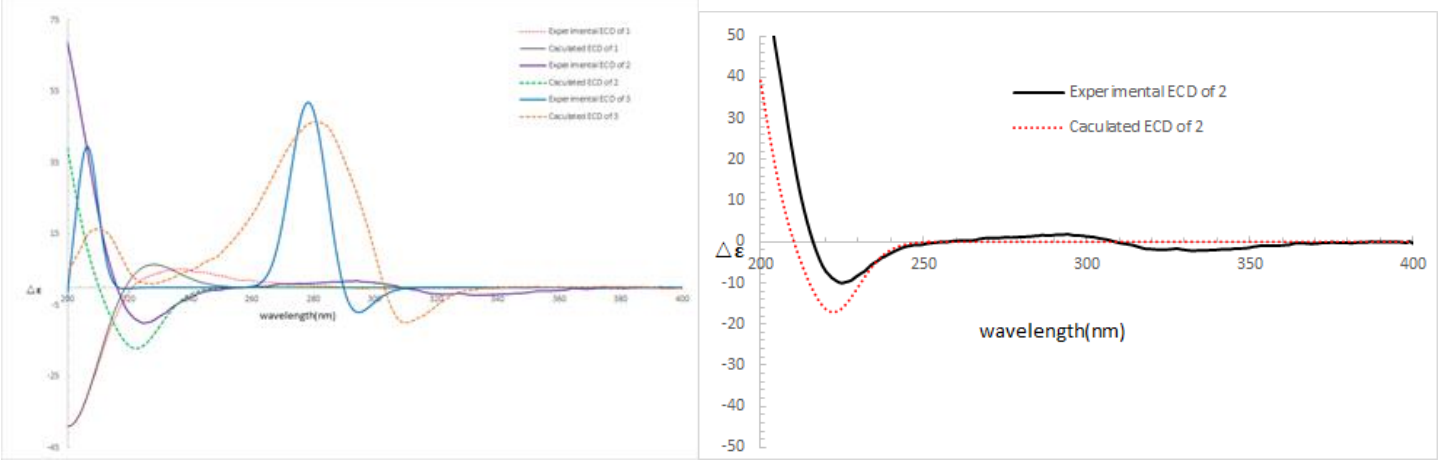

b3lyp/6-311 $+g(d, p)$ optimized lowest energy 3D conformer of 2

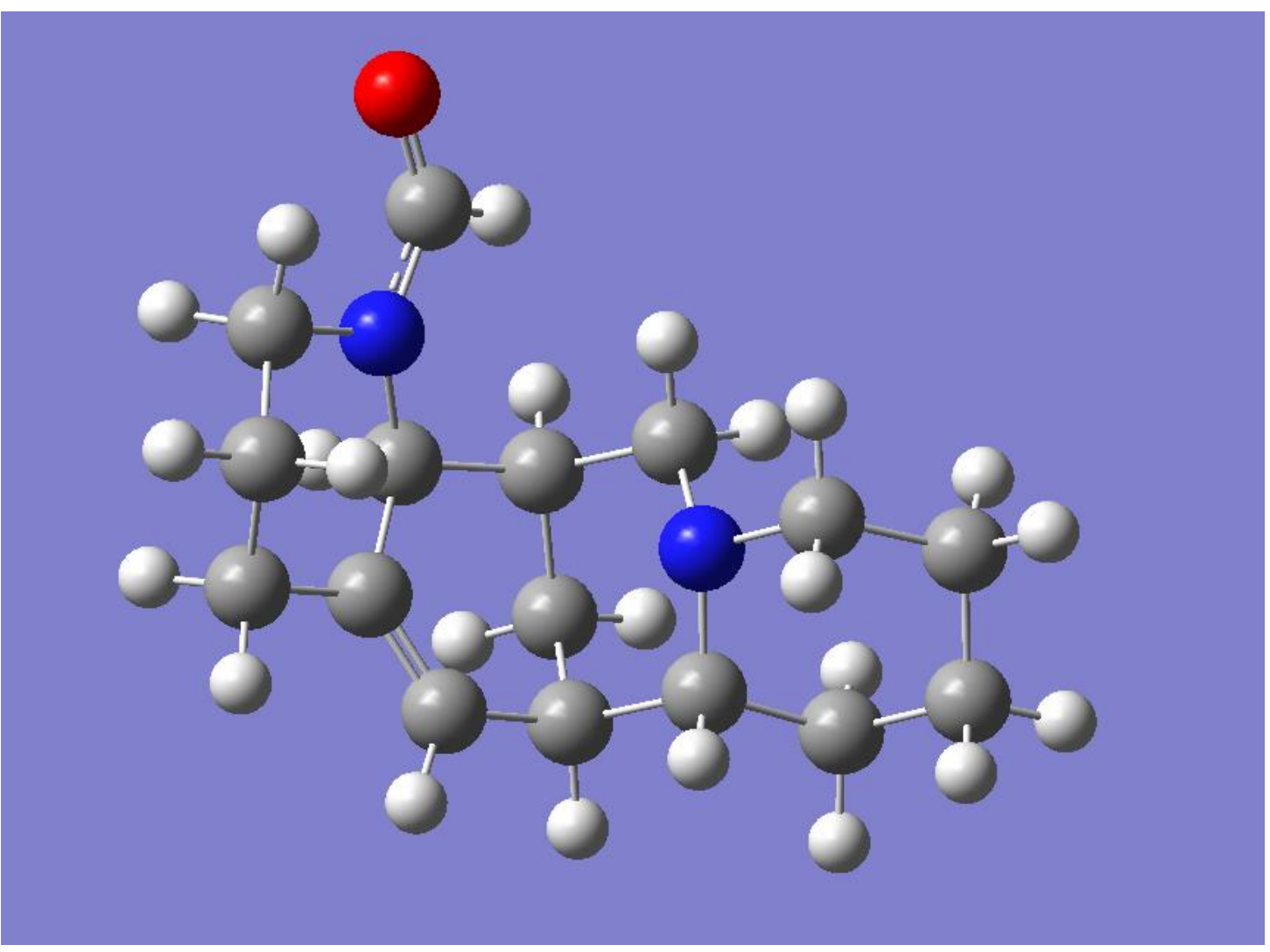


Absolute confirguration of 2<smiles>O=CN1CCCC2=C[C@@H]3CCCC[C@H]3C2C1</smiles>

2

Computational methods for ECD of compound 2

$\mathrm{td}=(50-50$, nstates $=50)$ cam-b3lyp/tzvp scrf=(solvent= methanol)

Input orientation:

\begin{tabular}{|c|c|c|c|c|c|}
\hline \multirow{2}{*}{$\begin{array}{l}\text { Center } \\
\text { Number }\end{array}$} & \multirow{2}{*}{$\begin{array}{l}\text { Atomic } \\
\text { Number }\end{array}$} & \multirow{2}{*}{$\begin{array}{l}\text { Atomic } \\
\text { Type }\end{array}$} & \multicolumn{3}{|c|}{ Coordinates (Angstroms) } \\
\hline & & & $x$ & Y & Z \\
\hline 1 & 6 & 0 & -4.245606 & 0.398528 & -0.537578 \\
\hline 2 & 6 & 0 & -3.448246 & 1.662162 & -0.892828 \\
\hline 3 & 6 & 0 & -2.049637 & 1.283819 & -1.414286 \\
\hline 4 & 7 & 0 & -1.295247 & 0.411439 & -0.513645 \\
\hline 5 & 6 & 0 & -2.048767 & -0.804764 & -0.178512 \\
\hline 6 & 6 & 0 & -3.445178 & -0.510368 & 0.410061 \\
\hline 7 & 6 & 0 & -0.683459 & 1.104852 & 0.615733 \\
\hline 8 & 6 & 0 & 0.190266 & 0.182994 & 1.491151 \\
\hline 9 & 6 & 0 & -0.677674 & -0.996236 & 1.955103 \\
\hline 10 & 6 & 0 & -1.170401 & -1.730850 & 0.702411 \\
\hline 11 & 6 & 0 & 0.024868 & -2.189454 & -0.091971 \\
\hline 12 & 6 & 0 & 1.484985 & -0.384504 & 0.843777 \\
\hline 13 & 7 & 0 & 2.327105 & 0.649707 & 0.178075 \\
\hline 14 & 6 & 0 & 3.399194 & 0.223260 & -0.737413 \\
\hline 15 & 6 & 0 & 2.937370 & -0.850306 & -1.710741 \\
\hline 16 & 6 & 0 & 2.357908 & -2.034972 & -0.932020 \\
\hline 17 & 6 & 0 & 1.207139 & -1.570250 & -0.079997 \\
\hline 18 & 1 & 0 & -2.211979 & -1.326794 & -1.132875 \\
\hline 19 & 6 & 0 & 2.483053 & 1.888685 & 0.732163 \\
\hline 20 & 8 & 0 & 3.326435 & 2.706591 & 0.400192 \\
\hline 21 & 1 & 0 & 2.084666 & -0.793847 & 1.676560 \\
\hline 22 & 1 & 0 & -5.209363 & 0.662335 & -0.090750 \\
\hline 23 & 1 & 0 & -4.470446 & -0.154886 & -1.459122 \\
\hline 24 & 1 & 0 & -3.976358 & 2.250528 & -1.650898 \\
\hline 25 & 1 & 0 & -3.356453 & 2.302925 & -0.007921 \\
\hline
\end{tabular}




$\begin{array}{llllll}26 & 1 & 0 & -1.451558 & 2.178290 & -1.612143 \\ 27 & 1 & 0 & -2.159277 & 0.756872 & -2.371562 \\ 28 & 1 & 0 & -3.978497 & -1.453683 & 0.573850 \\ 29 & 1 & 0 & -3.355416 & -0.025972 & 1.388625 \\ 30 & 1 & 0 & -0.094614 & 1.927313 & 0.204661 \\ 31 & 1 & 0 & -1.423682 & 1.563858 & 1.298295 \\ 32 & 1 & 0 & 0.476889 & 0.764020 & 2.372460 \\ 33 & 1 & 0 & -0.104531 & -1.680104 & 2.588791 \\ 34 & 1 & 0 & -1.511370 & -0.624020 & 2.557383 \\ 35 & 1 & 0 & -1.777665 & -2.597375 & 0.985309 \\ 36 & 1 & 0 & -0.109885 & -3.047169 & -0.747486 \\ 37 & 1 & 0 & 3.748338 & 1.116940 & -1.251590 \\ 38 & 1 & 0 & 4.246971 & -0.156169 & -0.146708 \\ 39 & 1 & 0 & 2.178532 & -0.442833 & -2.386258 \\ 40 & 1 & 0 & 3.790407 & -1.164060 & -2.320182 \\ 41 & 1 & 0 & 2.026951 & -2.832726 & -1.601565 \\ 42 & 1 & 0 & 3.150381 & -2.455888 & -0.295450 \\ 43 & 1 & 0 & 1.758582 & 2.116129 & 1.525718\end{array}$

3. ECD spectra calculation of 3

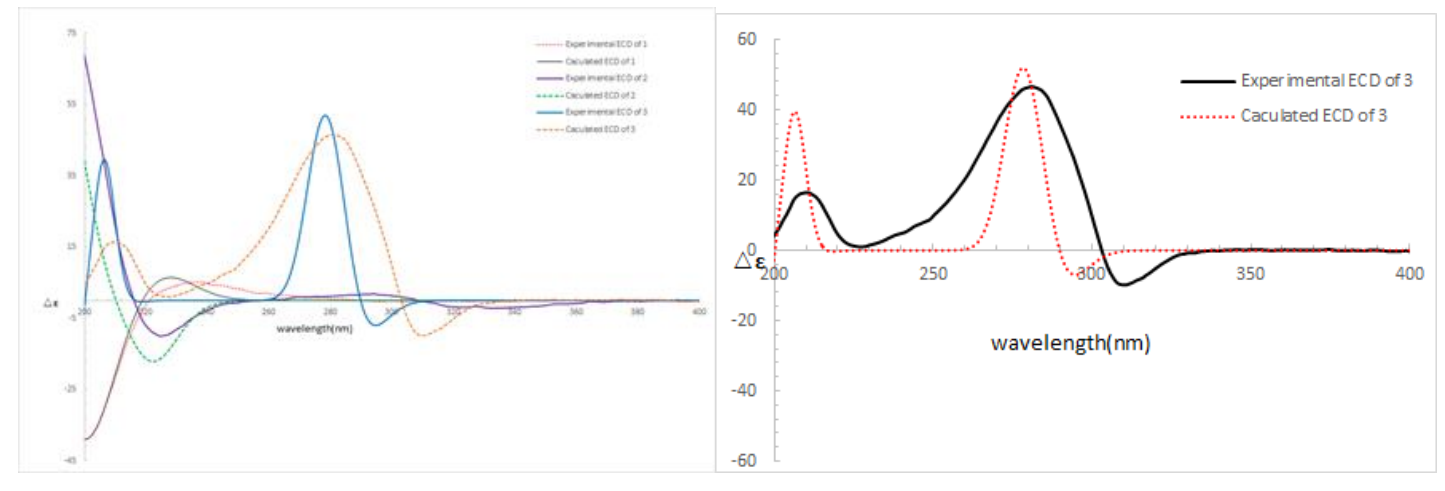

b3lyp/6-311 $+g(d, p)$ optimized lowest energy 3D conformer of 3 


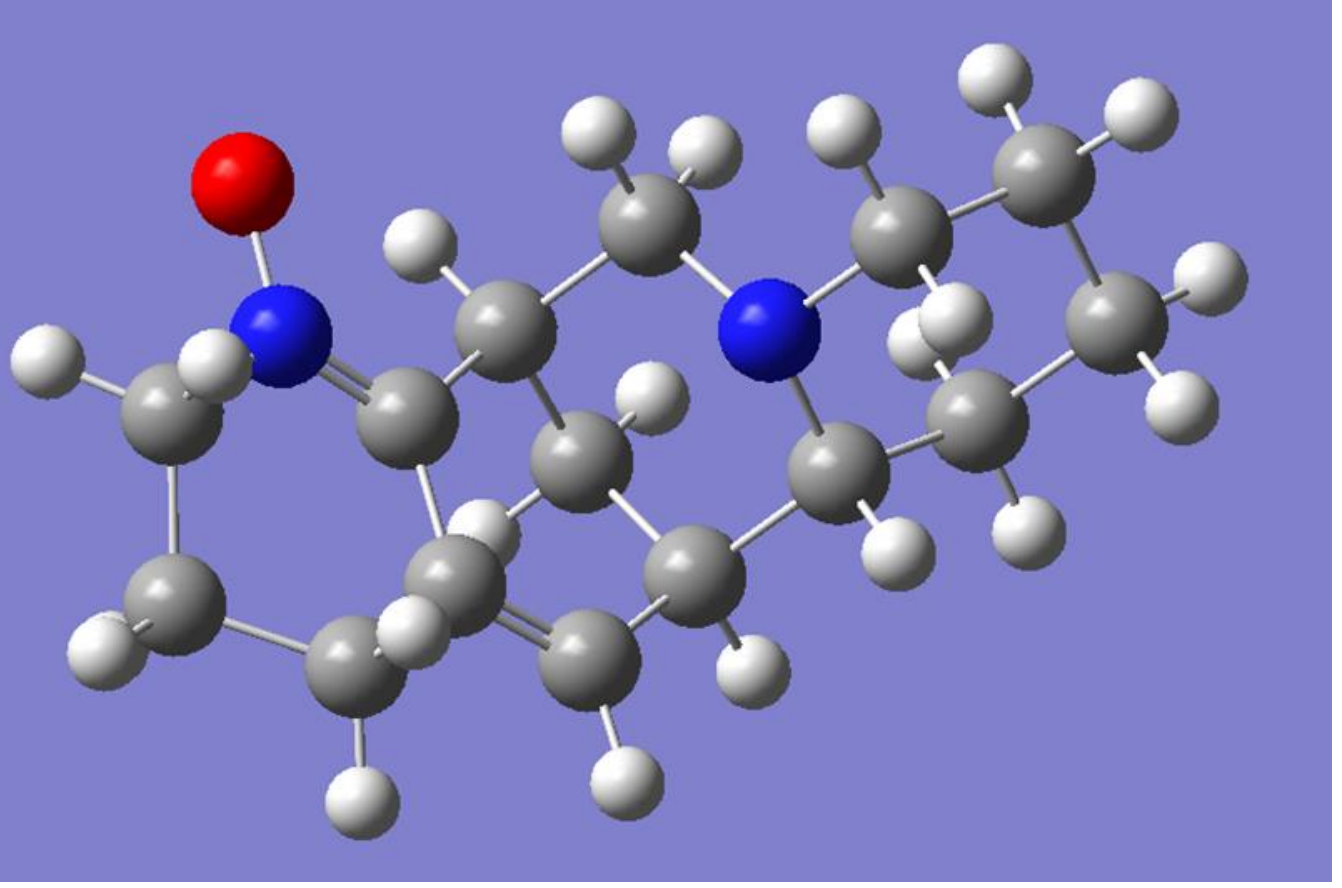

Absolute confirguration of 3

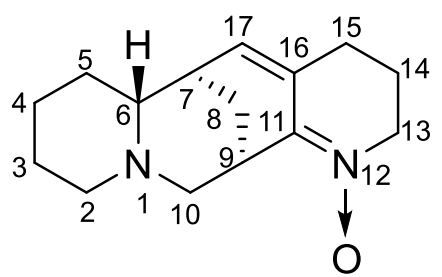

3

\section{Computational methods for ECD of compound3}

$\mathrm{td}=(50-50$, nstates $=50)$ cam-b3lyp/tzvp scrf $=($ solvent $=$ methanol $)$

Input orientation:

\begin{tabular}{crrrrr} 
Center & Atomic & Atomic & \multicolumn{3}{c}{ Coordinates (Angstroms) } \\
Number & Number & Type & X & $Y$ & Z \\
-1 & 6 & 0 & 4.206251 & 0.154151 & -0.365803 \\
2 & 6 & 0 & 3.693056 & -1.218033 & -0.825739 \\
3 & 6 & 0 & 2.285443 & -1.085678 & -1.435224 \\
4 & 7 & 0 & 1.317692 & -0.424445 & -0.559264 \\
5 & 6 & 0 & 1.797813 & 0.898214 & -0.124717 \\
6 & 6 & 0 & 3.185224 & 0.845651 & 0.552436
\end{tabular}


40

0.774305

$-0.328788$

0.272963

0.716419

$-0.491717$

$-1.495544$

$-2.451289$

$-3.670515$

$-3.951225$

$-2.692484$

$-1.526023$

1.919165

$-2.411114$

5.171160

4.380608

4.374078

3.666412

1.886811

2.354072

3.514910

3.126394

0.356959

1.532042

$-0.691827$

1.114256

$-0.460643$

1.160708

$-0.497487$

$-3.516242$

$-4.467563$

$-4.783784$

$-4.262386$

$-2.849458$

$-2.455160$
$-1.285107$

0.493205

$-0.556837$

1.288330

0.715155

1.899477

1.613408

0.735645 1.949701

$-0.103235$

$-0.189877$

0.406622

$-1.086160$

0.247129

$-0.802287$

$-0.560430$

0.687350

$-0.693707$

1.406566

$-1.179888$

1.100712

$-0.267826$

1.486016

$-1.046380$

$-2.265895$

0.752945

0.056101

0.141751

0.785997

$-1.247074$

$-1.656767$

$-1.563134$

$-1.907856$

0.025863

$-2.066516$

$-1.710733$

$-0.498089$

$-2.360844$

1.863956

0.788045

0.305787

1.503734

$-2.177266$

0.020122

$-1.629723$

1.220303

$-1.241971$

2.056748

0.449902

2.546016

1.239324

2.518334

2.539328

1.115418

2.898643

$-0.633120$

$-1.276024$

$-1.534433$

$-1.339953$

$-0.048392$

0.832964

$-1.387799$

1.090279

0.275712

2.486217

$-1.238655$

$1.062514-2.194971$ 